\title{
CORTESANÍA Y HUMANISMO EN EL DEBATE SOBRE LA MUJER: ALFONSO DE CARTAGENA Y SU DUODENARIUM
}

\author{
POR \\ LUIS FERNÁNDEZ GALLARDO ${ }^{1}$ \\ UNED (Albacete)-SEMYR
}

\begin{abstract}
RESUMEN
Alfonso de Cartagena (1385-1456) escribió su Duodenarium (1442) a instancias de Fernán Pérez de Guzmán. Se trata de la respuesta a una serie de cuestiones; la última se refiere al debate de la mujer: ¿qué excelencia es mejor, la femenina o la masculina? Sostiene la superioridad de una mujer, la Virgen, sobre cualquier otro ser humano y analiza las virtudes propias de hombres (fortaleza, justicia) y mujeres (modestia, recato). Vindica la excelencia femenina mediante tres diálogos - revelador de una elaboración literaria, pero se le impuso a don Alonso el modelo del diálogo-disputa de tradición medieval- de tres parejas excelsas, correspondientes a los tres estadios de evolución moral: ley natural (Lucrecia y Catón), ley vieja (Susana y José) y ley nueva (reina Berenguela y Fernando III de Castilla). Sus ideas sobre la mujer y el matrimonio son conservadoras, rigoristas: marginación de la sexualidad y defensa firme del consentimiento parental. Completa éstas el comentario del elogio bíblico de la buena esposa (Proverbios 31), anticipo de La perfecta casada de Fray Luis de León.
\end{abstract}

PALABRAS CLAVE: debate sobre la mujer; literatura cortesana; Castilla; siglo XV; Alfonso de Cartagena.

\section{COURT AND HUMANISM IN THE GENDER DEBATE. ALFONSO DE CARTAGENA AND HIS DUODENARIUM}

\begin{abstract}
Alfonso de Cartagena (1385-1456) wrote his Duodenarium at the request of his friend Fernán Pérez de Guzmán. It is about six questions. The last refers to the gender debate: What sort of excellence is the best, that of men or that of women? He holds that a woman, Virgin Mary, is over any human being and analyzes the virtues of men (fortress, justice) and women (modesty, honesty). He vindicates the excellence of women by means of three dialogues, that correspond to three stages of moral evolution: natural law (Lucretia, Cato), old law (Susan, Joseph), new law (Queen Berenguela, Fernando III). He uses a literary device, not in the manner of the humanistic dialogue, but in that of the medieval disputatio. His ideas about women and marriage are conservative and rigorous. He margins sexuality and defends parental consent. He ends the question with the commentary of the biblical praise of the good wife, an interesting precedent of Fray Luis de León's La perfecta casada.
\end{abstract}

KEY WORDS: debate about women; courtly literature; Castile; 15th Century; Alfonso de Cartagena.

Cómo CITAR este artículo / Citation: Fernández Gallardo, Luis. 2020. "Cortesanía y humanismo en el debate sobre la mujer: Alfonso de Cartagena y su Duodenarium». Hispania Sacra LXXII, 145: 79-93. https://doi.org/10.3989/hs.2020.006

Recibido/Received 21-02-2019

Aceptado/Accepted 25-01-2020

1440. Alfonso de Cartagena había vuelto a Castilla de su misión diplomática en Basilea, que se extendió por espacio de seis años. A lo largo de ellos acumuló una amplia experiencia política, eclesiástica y literaria. A ello contribuyó poderosamente su gran receptividad a las novedades cultu-

1 Ifernandez@albacete.uned.es / ORCID iD: https://orcid.org/0000-0002-5012-9166 rales, su apertura de mente, que halla en su fascinación por el gótico germánico icónica manifestación: así lo atestiguan las agujas caladas de las torres de la catedral de Burgos, que con magnificencia mandó construir. Volvía aureolado por el prestigio de sus gestas como letrado, tanto en el ámbito curial como en el erudito y literario. Tenía entonces unos 55 años y se hallaba en la plenitud de sus facultades intelectuales y en la cima de su carrera eclesiástica y política 
- había conseguido la dignidad episcopal en el transcurso de dicha misión. Prestigio cimentado, pues, en una intensa actividad tanto diplomática como erudita y académica. Los apuntes biográficos que de él trazó Fernando de Pulgar para su galería de varones ilustres de Castilla recogen ambas facetas: la fama alcanzada en el concilio basiliense por "su ciencia y la esperiencia de sus letras y claras costumbres", por la que el papa Eugenio IV «le proveyó del obispado de Burgos", y su actividad literaria, en la que destaca la polémica mantenida con Leonardo Bruni en defensa de la versión latina tradicional de la Ética Nicomáquea de Aristóteles, «en la qual disputa se contienen muchos y muy dotrinables precebtos». ${ }^{2} \mathrm{~A}$ la polémica con Bruni, que se desarrolló en Basilea - aunque las Declinationes estaban redactadas antes de su partida hacia Basilea-, hay que añadir otra asimismo importante: el debate académico que sostuvo con el célebre canonista Ludovico Pontano (1409-1439), a la sazón protonotario apostólico y una de las lumbreras del sínodo basiliense. Este episodio, solo conocido por la repuesta de don Alfonso a una repetitio que aquél pronunció sobre un capítulo del libro VI del Liber extra o Decretales de Gregorio IX (1234), el Tractatus super repetitione Ludovici de Roma, ${ }^{3}$ es sumamente revelador del prestigio extraordinario de que gozaba en los círculos académicos de Basilea, en tanto que fue insistentemente requerido por el jurista italiano a que disputara con él.

\section{Don Alfonso, mentor intelectual en la CAStilla del SIGLO XV.}

No es de extrañar, por tanto, que fuera solicitado en repetidas ocasiones por aquellos nobles ilustrados que participaban del interés por las formas de cultura letrada y constituían ese nuevo público lector laico que hallaba en la epístola cauce idóneo para el desarrollo de una nueva cultura. ${ }^{4} \mathrm{~A}$ tal impulso obedece casi toda su obra literaria original, compuesta precisamente tras su regreso de Basilea. Fernán Pérez de Guzmán (ca. 1377-ca. 1460) fue el más afortunado de los aristócratas peticionarios: a diferencia de la renuencia que mostraría don Alfonso con Pedro Fernández de Velasco, conde Haro, respondió con suma diligencia a los requerimientos del señor de Batres. Precisamente tal diligencia permitirá revelar las limitaciones del humanismo castellano del siglo XV: la resignada conformidad con la variante vernácula ${ }^{5}$ debido a la precaria latinidad de la nobleza hispana, como pone de manifiesto el paso del latín al castellano en dos obras dedicadas a este magnate.

Hacia 1440 Pérez de Guzmán es probable que, lejos de hallarse enteramente retirado del tráfago político en su solar de Batres, entregado a la meditación y a la lectura, ${ }^{6}$ estuviera metido de lleno en tales negocios, si es que la observación que al respecto hiciera Alfonso de Cartagena

\footnotetext{
2 Pulgar 1985, 140-141.

3 Cfr. Archivo General de Simancas, Estado. Francia, leg. K-1711, ff. 279rㅇ-291rㅇ․

4 Lawrance 1988, 81-99.

5 Conforme a la feliz expresión, humanismo vernáculo, acuñada por Lawrance 1986, 63-79. Para su incardinación en el movimiento humanístico véase Fernández Gallardo 2000, 66-67.

6 Cfr. Tate 1965, x. Erige el exilio en clave para la interpretación de su obra poética, centrada en sus dos poemas mayores, Weiss 1991a, que, por lo demás, ofrece una perspicaz lectura de tales obras.
}

en el prólogo a su Duodenarium respondía a la realidad y no era mero expediente para ponderar la vocación estudiosa de su amigo. ${ }^{7}$ Es asimismo probable que estuviera presente en los enfrentamientos que se desarrollaron en Medina del Campo entre mayo y junio de 1441, pues de nuevo don Alfonso lo hace testigo de tales acontecimientos, si es que el plural "conspeximus» incluye realmente, cual sociativo, al destinatario del texto. ${ }^{8}$ Sumido, pues, en la intensa actividad política de aquellos años, en que se dirime el conflicto entre la nobleza, representada por la Liga, y don Álvaro de Luna, ${ }^{9}$ aún hallaba tiempo para entregarse al estudio y al cultivo de las letras. Tal es la circunstancia biográfica en que adquiere pleno sentido la petición que hizo a su amigo don Alfonso y está en la base de la composición del Duodenarium. Desde el compromiso en las interminables querellas por el control del Consejo Real, pieza clave del entramado institucional de la monarquía trastámara, Pérez de Guzmán debió de quedar hondamente impresionado por el prestigio que como curial y hombre de letras se había forjado su amigo Alfonso de Cartagena durante la larga misión desempeñada como embajador del rey de Castilla (1434-1439).

Tal vez sabedor de los vínculos personales y literarios que había establecido el prelado burgalés con destacados humanistas italianos, quiso participar de ese comercio intelectual que tenía como vehículo la epístola ${ }^{10}$ y era transmisor de unos nuevos valores culturales. Y para ello comunicó a su amigo sus inquietudes, sus intereses intelectuales. Le envió una carta en castellano en que planteaba doce cuestiones. Esta epístola se ha perdido y con ella la relación de las cuestiones. ${ }^{11}$ Solo son conocidas las cuatro a que respondió don Alfonso: un variado repertorio de temas que van desde la alta política a los debates cortesanos. He aquí las circunstancias en que se gestó el Duodenarium, cuya fecha de composición cabe establecer con cierta precisión: desde la primera semana de 1442 hasta fines de julio de ese mismo año. ${ }^{12}$ Se trata, pues, del momento inmediatamente posterior al regreso de Basilea, en que la talla de su fama como curial y hombre de letras había aumentado considerablemente en los círculos ilustrados castellanos.

7 «Quod cum te sub curialium tumultuum fragoribus laborantem talis ymaginacio mouit ut me illis interpellares questionibus, que nec pecuniam pariunt nec ad rem familiarem conferre videntur, illud ut cogitem vis: quid facturus esses, si sub quieto occio tranquillos domi dies pertransssires?» (Alfonso de Cartagena, Duodenarium, apud Fernández Gallardo y Jiménez Calvente 2015, 162). Para el contexto de tales años véase Fernández Gallardo 2002, 269.

8 «Post uero congregatis exercituum cuneis qui ex utroque latere vagabantur, Metine et prope Metynam ymaginem quandam belli Troiani conspeximus...» (Duodenarium, 166).

9 Que por entonces se inclinaba en favor de la Liga (Suárez Fernández 1975, 151-153).

10 La epístola era uno de los géneros dilectos de los humanistas (Harth 1983, 81), a tal punto que gustaban de dar forma epistolar al discurso filosófico o académico (Kristeller 1974, 12-13). Para su importancia en el panorama cultural castellano del Cuatrocientos véase Lawrance 1988, 85-87.

11 Así lo constata el propio Cartagena, destacando la diferencia de lenguas entre preguntas y respuestas, que fundamenta sobre criterios estamentales (Duodenarium, 261), prestando así ocasión a una briosa vindicación de la elocuencia vernácula (Fernández Gallardo 2012a). De dicha epístola cabe hacerse una idea por la que envió a don Alfonso para que le instruyera sobre la excelencia, mérito y fruto de la oración (apud Pérez de Guzmán 1924, 217-221).

12 Fernández Gallardo 2012b, 184-185. 
La génesis de este texto capital en la introducción del humanismo en la Castilla del siglo XV es, pues, ilustrativa del dinamismo cultural que cundía entre un reducido pero selecto sector de la aristocracia castellana y que se manifestaba en un afán de coleccionismo bibliófilo y en una incansable búsqueda de nuevos saberes mediante el patrocinio de traducciones de autores antiguos y el requerimiento directo de letrados versados en la lengua latina. De la biblioteca de Fernán Pérez de Guzmán ha quedado el valioso testimonio del inventario de sus bienes. ${ }^{13}$ En cuanto a sus solicitaciones, a más del Duodenarium, el Oracional del propio Cartagena es testimonio de los afanes intelectuales del señor de Batres, que se extienden asimismo a la depuración y renovación del sentimiento religioso, como revela la carta mensajera que dirigió a Fray Gonzalo de Ocaña, pidiéndole la traducción al castellano de los diálogos de san Gregorio Magno. ${ }^{14}$

La respuesta a la petición de Pérez de Guzmán no se hizo esperar. Don Alfonso tomó la péñola y acometió la resolución de las cuestiones conforme al rigor que preside su quehacer intelectual: una exposición sistemática sobre la lengua original, las dignidades imperial y regia, la excelencia de los reyes hispanos y, finalmente, el sempiterno debate de los sexos. ${ }^{15}$ La serie de respuestas fue adquiriendo tales proporciones que decidió no esperar a su total resolución, sino remitirlas conforme las iba completando, agrupadas en pares, que denominó "binaria». Pero, finalmente, consciente del enorme esfuerzo requerido desistió de rematarla, quedando inconcluso un ambicioso proyecto en el que se advierte el empeño por introducir entre la élite caballeresca formas de cultura que se situaban en la órbita de los studia humanitatis.

\section{CARTAGenA EN El DEBATE SOBRE LA MUJER}

La cuarta cuestión es sumamente expresiva de la encrucijada de corrientes culturales que viene a constituir el panorama literario castellano de mediados del siglo XV: "Qvis laudabilior, mirabilior ac melior reputari debet, optimus vir an optima mulier?». ${ }^{16}$

Desde la perspectiva del peticionario se enmarca en el debate sobre la mujer, ámbito dilecto de la cortesanía literaria. ${ }^{17}$ Si bien Pérez de Guzmán no se mantenía al margen de las modas cortesanas, su participación en los juegos literarios de la corte $^{18}$ no se llevaría a cabo sin que la índole esencialmente grave de su temple intelectual dejara de pro-

\footnotetext{
13 Ejemplarmente estudiado por Vaquero 2003.

14 Apud Pérez de Guzmán 1924, 209-215.

15 Ofrecen un análisis de la doctrina desarrollada en ellas Fernández Gallardo y Jiménez Calvente 2015, 69-94.

16 Duodenarium, 385.

17 Ofrece un espléndido encuadre del debate en el marco de sus manifestaciones prosísticas Gómez Redondo 2002, 3220-3340. Para la contribución de Cartagena véase Ríos de la Llave 2018 (especialmente pp. 220-226). Asimismo, Vélez-Sainz 2015, 31-165, la antología y estudio de Archer 2001 y la bibliografía reunida por Weiss 2002.

18 Así define el amor cortés uno de los más autorizados medievalistas: "La fine amour est un jeu. Éducatif. C'est l'exact pendant du tournoi» (Duby 1990, 75). Subraya la dimensión lúdica de la erótica cortesana Weiss 1991b, 242 (formula su tesis: «... courtly lovers were indeed playing a game, but it was a game that constructed and institutionalized a particular set of values based on class and, particularly, gender»).
}

yectarse, reconduciendo la frívola expectativa del debate de sexos hacia una reflexión de tipo antropológico. En efecto, la sólita confrontación de varones y mujeres se sitúa en una tesitura que además de cuestiones propias de la vida social, como la reputación, el honor, implica una consideración de los fundamentos de la ética, pues se trata de enfrentar dos tipos de excelencia moral. Y, de hecho, los términos con que se formula la cuestión - hay que suponer que don Alfonso traduce fielmente el texto castellano de Pérez de Guzmándelatan la impronta de la doctrina ética aristotélica, pues lo que suscita alabanza y admiración, esto es, el origen del honor no es otra cosa que la virtud. ${ }^{19} \mathrm{~A}$ su vez, el obispo de Burgos desarrollaría latamente la perspectiva eminentemente ética de la cuestión, centrada en el análisis de las virtudes.

No era ésta la primera ocasión en que don Alfonso intervenía en el debate sobre sexos, que se advierte intenso en las letras castellanas del Cuatrocientos. Con ocasión de su traducción del tratado senequista De providentia (ca. 14321434), ${ }^{20}$ hubo de pronunciarse al respecto. El hecho de ser una obra patrocinada por el rey Juan II de Castilla determinaba un ámbito de recepción cortesano, por lo que la opinión de Séneca, dada la autoridad que gozaba $-y$ que el propio traductor se encargaría muy bien de justificar $-{ }^{21}$ exigía su detenida consideración. Y es el caso que el gran moralista cordobés deslizó una afirmación misógina que hubo de suscitar la discusión de los lectores cortesanos. De ahí que Cartagena se sintiera movido a dedicar una glosa al locus en cuestión.

Se advierte en tal planteamiento la ponderación propia de su temple intelectual. Diríase que sigue una forma de argumentar propia de la metodología escolástica, en la medida en que enuncia en primer lugar los argumentos que se propone refutar, los testimonios aducidos de la Escritura y de las crónicas, incluidas las hispanas, para mostrar, a continuación, lo incorrecto de inducir la universal perversión de la mujer a partir de casos particulares. Reivindica una ceñida exégesis del texto bíblico alegado en contra de las mujeres, limitando el alcance de la invectiva contra la mujer, conforme a los principios del Derecho Civil. Así, frente a una visión sesgada y unilateral, solo atenta a los casos de mujeres perversas, Cartagena muestra a santas y a aquellas otras féminas de cuya virtud dejaron testimonio las crónicas, de que se colige la justa retribución de elogios y censuras, conforme al mérito o la culpa de la mujer: "Por e(n)de, no(n) son de culpar todas por la culpa de algu(n)as, ca si así fuese, ta(m)bién serían de culpar todos los o(m)bres, pues ouo (e) ay algu(n)os malos. Más razonable es $q(u e)$ las malas aya(n) su iusta su rep(re)he(n)sión (e) las buenas dignas alaba(n)ças...». ${ }^{22}$

19 Cfr.: «... el honor es el premio de la virtud...» (Aristóteles 1988, 220). Estamos ante un caso conspicuo de lo que con relación al corpus doctrinal aristotélico podría denominarse tradición difusa, como propuse en Fernández Gallardo 1996, 72.

20 Para la cronología de las traducciones de Séneca que llevó a cabo Cartagena véase Fernández Gallardo 2012b, 115-116.

21 No solo en las piezas liminares de sus traducciones senequistas, sino muy especialmente en sus Declamationes, donde sostiene la superioridad de Séneca sobre Cicerón (Fernández Gallardo 2012b, 100-101).

22 Cartagena 1491: sig. tip. n iiij (5) ro (glosa A todas). Don Alfonso no escribió ningún Tratado de mugeres como sugiere el ensayo bibliográfico sobre la literatura hispánica misógina y en defensa de la mujer del Medievo e inicios de Renacimiento elaborado por Weiss 2002, 
La autoridad de que gozara el sabio prelado burgalés consagraría su equilibrada vindicación de la naturaleza moral de la mujer como argumento de quienes se oponían a las diatribas misóginas. Así, Fernando de la Torre, reprodujo las glosas de don Alfonso en una de sus cartas, en que mostraba la excelencia virtuosa de las mujeres. ${ }^{23}$

\section{EN LA PALESTRA CORTESANA}

Curtido diplomático, urgido a declararse en el debate sobre sexos, Alfonso de Cartagena opta por mantenerse al margen de la dialéctica cortesana. Sugiriendo con cierta dosis de malicia que se le estuviera tendiendo una trampa, la elude con sagacidad y, absteniéndose de formular una conclusión en uno u otro sentido, se acoge a la función de relator, esto es, de letrado que elabora la documentación del expediente, para ofrecer al peticionario los criterios precisos para que pueda formarse su propia opinión. ${ }^{24}$ Por ello, si en un principio pareciera que don Alfonso delata cierta misoginia al permitirse dirigir un inocuo dardo contra la condición más impulsiva de las mujeres, al punto ofrece un argumento terminante en pro de las féminas, apelando a la irrefragable superioridad de la Virgen sobre cualquier otro ser humano excelente. ${ }^{25}$

El obispo de Burgos iniciaba el desarrollo de la cuestión procediendo a una solemne declaración que dejaba salvaguardada la ortodoxia ante los derroteros que podía tomar el debate: la esencial igualdad de hombres y mujeres como cristianos, esto es, la igualdad en la recepción de la gracia y la salvación. Ante todo, se manifestaba una robusta fe desde la que se sugería la futilidad de tal debate. ${ }^{26}$ Sobre cualquier consideración antropológica previa se imponía un principio teológico: la esencial comunidad del género humano, recipiendario del mensaje salvífico y de la acción redentora del Salvador. La aspiración a la vida eterna, a lo que con léxico filosófico de impronta aristotélica se denominó summum bonum, relegaba cualquier división en la condición humana que limitara la dimensión ecuménica del mensaje cristiano: ciertamente resultaban premonitorias tales reflexiones desde la perspectiva del problema converso que estallaría al final de la década a raíz de la promulgación del primer estatuto de limpieza de sangre en el marco de la rebelión de Toledo de 1449.

276. Dicho título remite a un apartado del libro $\mathrm{V}$ de los Cinco libros de Séneca. Se trata simplemente de una glosa, ciertamente de amplia extensión. Identificó correctamente el supuesto tratado con la glosa Accorsi 2009, 78.

${ }^{23}$ Torre 2009, 178-179. Se ha vinculado asimismo las glosas de Cartagena con la Defensa de virtuosas mujeres de Diego de Valera (cfr. Accorsi 2009,81$)$, aunque, habría que referir más bien tal vínculo con el Duodenarium.

24 «Determinacionem ac eleccionem ex illis elicere intactam ac integram tibi aliiue cuicumque lectori dimittam, nec enim diffinitoris, set ut cuiusdam relatoris in hoc officium summo» (Duodenarium, 384).

25 De ahí que encabece, infringiendo el orden cronológico, la serie de mujeres ilustres reunida por Álvaro de Luna en su obra en defensa de las mujeres (Luna 2009, 159-161). Hay que tener en cuenta que se ha sugerido la autoría de Alfonso de Cartagena de parte de esta obra (Morrás 1991, 235). Sin embargo, esta misma estudiosa no parece contemplar esta hipótesis en Morrás 2003, 93-127.

26 «Quid ergo alter sexus alteri improperare potest, cum uterque ad summo bono fruendum capacissimus est? [...] Cesent ergo contenciose querele ac supersticiose emulaciones inter virilem ac femineum sexum, cum uterque inefabilem honorem accepit et supremorum bonorum dotem habere, si voluerit, valebit» (Duodenarium, 384, 386).

\section{VIRTUDES DE LAS NATURALEZAS MASCULINA Y FEMENINA}

Una vez salvaguardada una ortodoxia que podía verse comprometida en el fragor polémico, el prelado burgalés procede a los necesarios deslindes para el adecuado desarrollo de la cuestión. Y puesto que ésta involucraba la doctrina moral, antepone los fundamentos de ésta a cualquier otra consideración. Al formularla en tales términos, Pérez de Guzmán no estaba sino proponiendo la confrontación del hombre más virtuoso con la mujer más virtuosa, la excelencia viril y la excelencia femenina. Mas en este punto, la mente preclara de don Alfonso advierte lo inadecuado de un planteamiento tal. ${ }^{27}$ En efecto, la virtud, la excelencia, ha de predicarse de alguien de acuerdo con su naturaleza, conforme a la doctrina aristotélica de la virtud como modo de ser. ${ }^{28}$ La esencial heterogeneidad de ambos sexos, una vez afirmada su comunidad desde la perspectiva del plan salvífico, exigía plantearse previamente la índole de ambos para determinar cuáles son sus virtudes propias.

La diferencia esencial entre ambos sexos que se presentaba como evidente es la fortaleza y vigor corporales del varón frente a la debilidad femenina -Boccaccio, referente inexcusable en el desarrollo castellano del debate sobre la mujer, había añadido torpeza de mente-.$-{ }^{29}$ Asimismo evidente se ofrecía la constatación de la urgencia menor del apetito sexual de la mujer - o su conveniencia, que para la mentalidad de entonces tanto monta-. Cartagena transcribe la diferencia natural en términos morales y erige así fortaleza de ánimo y castidad en las virtudes propias de varones y mujeres respectivamente. ${ }^{30}$ Es de notar cómo el prelado burgalés se acoge a una suerte de communis opinio, a una estimación de tipo consuetudinario, como revela el verbo frecuentativo «solemus».

Mas no debió de encontrar tal planteo satisfactorio, pues la fortaleza por sí sola no hace bueno al hombre, como lo prueba el caso de varones perversos y asimismo fuertes. Por ello añadió, destacando que se trataba de su propia opinión, la virtud de la justicia para completar la excelencia viril: "Vellem namque ut boni viri nomen assumeret qui fortitudini mixtam haberet iusticiam ${ }^{31}{ }^{31}$

A su vez, la castidad se completa con la modestia y el recato para componer la excelencia femínea: «Feminam vero bonam dicamus illam que casta et modesta est ac quieta domi et a virorum conuentibus segregata...». ${ }^{32}$

Obviamente la lógica de la doctrina ética aristotélica no conducía necesariamente a la identificación de tales virtudes como correspondientes a las naturalezas respectivas de hombres y mujeres. Sobre el discurrir del prelado burgalés

27 Proceder que precisamente había adoptado Boccaccio en su vindicación de mujeres ilustres, al afirmar el mérito de aquellas féminas capaces de realizar grandes hazañas sin la fortaleza de que la naturaleza había dotado a los hombres (Boccaccio 2010, 60).

28 «Praemittendum tamen non incongrue puto ex qua virtute optimum virum feminamue optimam uocare solemus» (Duodenarium, 388). Cfr. Aristóteles 1988, 165-167.

29 Boccaccio 2010, 60. Una versión castellana de esta obra figuraba en la espléndida biblioteca del Marqués de Santillana (Schiff 1905, 346-347). Ofrece un preciso análisis de la concepción de la mujer Allen 2002, 276-311.

30 «Bonum ergo virum illum qui fortis, bona muero feminam eam que casta est uocare solemus». (Duodenarium, 394).

31 Duodenarium, 394.

32 Duodenarium, 396. 
gravitaban los valores sociales, culturales, religiosos, que se imponían de modo ineluctable, constituyendo las premisas de que parte el razonamiento ético. Y es que hasta ahora, parecía ir desarrollando sus argumentos in abstracto, sin anclaje en la realidad social.

Hay que partir de la base de que el debate de sexos al que se ve empujado don Alfonso tiene un preciso contexto social: se desarrolla en el marco de la cultura cortesana propia de la aristocracia castellana del siglo XV. Los galanes amadores, inolvidablemente evocados por Jorge Manrique en sus Coplas, acudían en defensa de las damas con las armas de la ciencia y la elocuencia frente a los ataques de las mesnadas misóginas, como evidencia el Libro de las virtuosas e claras mujeres de don Álvaro de Luna. El entorno cortesano iba a determinar los roles y valores sociales asumidos. Las virtudes viriles y femeninas no serán otras que las propias del estamento nobiliario. Para el varón, la excelencia se plasma en dos virtudes eminentemente caballerescas, fortaleza de ánimo y justicia. El perfil social de la fémina virtuosa queda más difuminado, en la medida en que el rol social de la mujer era más homogéneo, trascendía las diferencias estamentales.

En la consideración de la naturaleza del hombre preclaro gravitaba el modelo literario cuya tradición se hacía remontar en el Medievo al De viris illustribus de san Jerónimo ${ }^{33}$ y que en los medios humanísticos contaba con la aportación de Petrarca de idéntico título - no debía de ignorar don Alfonso esta obra, que sintonizaba plenamente con su concepción de la historia como repertorio ejemplar-.$^{34}$ La vindicación de una Antigüedad que se proponía como paradigma ejemplar determinó que el ideal heroico se modelara en el Bajo Medievo en tensión emuladora frente a los grandes hombres romanos y griegos. La caballería redefinía sus valores y su función social como consecuencia de su permeabilidad a las aportaciones del humanismo. La formulación de la excelencia viril que hacía el obispo de Burgos tenía, pues, un acusado componente estamental. No era sino una propuesta ejemplar para la nobleza, cuya función social era el ejercicio de las armas, cuyo sostenimiento, a su vez, reposaba sobre el regimiento de señoríos. Las virtudes que determinaban la excelencia del noble varón eran, pues, la fortaleza de ánimo para la guerra y la justicia para el gobierno señorial.

En cambio, para la mujer excelente el referente literario no era otro que el hagiográfico hasta la decisiva intervención de Boccaccio en defensa de la mujer. Matronas bíblicas, vírgenes y mártires compendiaban las virtudes femeniles. Al humanista florentino se debe la incorporación de las mujeres ilustres de la Antigüedad. Mas el peso de la realidad social limitaba la influencia de la nueva aretología femenina que aportaba el humanismo: el protagonismo que podía adquirir en la vida pública chocaba con la barrera prácticamente infranqueable de su incuestionable reclusión

33 Como revela el prólogo de Fernando de Pulgar a su galería de castellanos ilustres, en que define el marco de la tradición en que se inscribe su obra (Pulgar 1985, 82).

34 Poseía Santillana la versión italiana del De viris illustribus (Schiff 1905, 320-321). Para el lugar de esta obra en la tradición en que se inscribe Ruiz Arzálluz 2009. Para la circulación de esta obra en España véase el utilísimo apunte bibliográfico de Valero Moreno 2015a, 213. en el hogar y en el claustro ${ }^{35}$ y la abstención de cualquier pretensión de vida autónoma fuera de tales ámbitos.

Don Alfonso detalla con precisión la forma en que se hace patente el lugar de la mujer en la sociedad: precisamente una discreta, muy limitada visibilidad. Reclusión doméstica y apartamiento de las reuniones de hombres, ${ }^{36}$ en quienes se identifica en primer lugar un peligro para el mantenimiento de la castidad. Mas dicho alejamiento entrañaba no solo la evitación del riesgo de la castidad, sino la asunción de un papel social determinado por la modestia, pues mezclarse en esas reuniones de varones suponía implicarse en sus negocios, en la actividad fuera del hogar. De ahí que la modestia constituya una forma de prudencia, ${ }^{37}$ fundamento ésta de la virtud.

\section{VINDICACIÓN DE LA EXCELENCIA FEMENINA}

\subsection{Ante la tradición en favor de la mujer}

Don Alfonso, enemigo de extremos, había rechazado la imputación universal, la acusación indiscriminada contra todo el género femenino y, a su vez, había exhortado a la alabanza de las mujeres virtuosas: cacaso la Iglesia no había canonizado a mujeres que alcanzaron la santidad? No iba, por tanto, a escatimar elogios para la virtud femenina. De este modo, la respuesta a la cuestión propuesta implicaba un posicionamiento ante la tradición literaria en loor de la mujer. $Y$ es que el modo como la aborda diríase pone de manifiesto una reacción ante las formas del elogio femenino que entonces se revelaban más prestigiosas en la Castilla de mediados del siglo XV.

En efecto, si tuvo conocimiento de la obra de Boccaccio, el testimonio más conspicuo de los valedores de la excelencia femenina, cabría considerar la perspectiva histórica adoptada como un rotundo mentís de las estrategias encomiásticas del escritor florentino. El autor del Decamerón, deslumbrado por su admiración y fervor hacia la Antigüedad, centraba su esfuerzo panegírico en los méritos de las féminas paganas. Justificaba tal selección alegando que las virtudes de las santas mujeres ya habían sido tratadas «en libros singulares por hombres piadosos», en tanto que las de las paganas no habían sido aún inmortalizadas por la escritura en «volumen alguno especial». Sin embargo, no parece ser ésta la verdadera razón, sino más bien la estimación de una excelencia moral carente aún de la gracia de Cristo, que se descubre en la exhortación que dirige a la dedicataria para que reconozca la superioridad de las virtuosas paganas sobre quien había recibido el bautismo. ${ }^{38}$ Boccaccio descu-

35 Que halla espléndida formulación en el sintagma «encerrada doncella» del monólogo de Melibea en que lamenta las limitaciones sociales de la mujer: «iCómo te espantarás del rompimiento de mi honestidad y vergüenza, que siempre como encerrada doncella acostumbré tener!» (Rojas 2000, 219). Honestidad - encierro - costumbre social: he ahí delimitado el espacio que encierra la estimación social de la mujer en el Medievo.

${ }_{36}$ Don Alfonso refleja con claridad meridiana el reparto de papeles familiares de hombres y mujeres del Medievo: "Au sein du groupe domestique, il y avait d'autre part répartition des rôles. Aux hommes revenait l'action extérieure et publique; les femmes se trouvaient normalement cantonnées à l'interieur...» (Duby 1990, 119).

37 Como pone de manifiesto la definición que daba el Catholicon, el gran repertorio léxico tan frecuentado por Cartagena: «Modestus [...] i(d est) te(m)p(er)atus et discretus...» (Balbus 1460: s.v. modestus, f. 265oo).

38 Boccaccio 2010, 61, 57. 
bre en este punto el temple del humanista que contempla un horizonte de plenitud en la inmanencia moral, determinada por la naturaleza y aún no abierta a la trascendencia del mensaje cristiano. De ahí que contraponga el modelo de Cristo como acicate de la virtud de las santas y el «instinto natural» de las paganas. ${ }^{39}$

Frente a esa vindicación sin matices de la excelencia de los antiguos, el obispo de Burgos iba a poner las cosas en su sitio. Reconocimiento, sí, de las virtudes de las mujeres paganas, pero sin dejar el menor resquicio al de su superioridad. Y para su irrefragable demostración, nada mejor que la adopción de una perspectiva histórica, que revelaría las verdaderas dimensiones de las excelencias morales de paganas y cristianas.

Alfonso de Cartagena se acoge a un esquema histórico ternario que estructura la historia de la salvación del género humano en tres estadios evolutivos - no etapas, tramos cronológicos propiamente dichos, pues se solapan en el tiempo los dos primeros-: gentilidad, Ley Vieja (o de la Escritura) y Ley Nueva (o de la Gracia)..$^{40}$

Contempla el destino humano como proceso de progresiva perfección moral desde el estado natural, cuya excelencia tiene unos límites, hasta la redención del género humano. Efectivamente, la razón natural es solo un medio que ayuda a discernir el bien del mal, pero no garantiza la salvación, que procede de la Gracia y conduce a lo que el propio Cartagena denominaría «bienaventuranza perdurable». ${ }^{41}$ De este modo, quedaban desmontadas las pretensiones de Boccaccio a esa especie de preeminencia moral de la Antigüedad, pues la excelencia alcanzada en el marco de la naturaleza encontraba un límite infranqueable para culminar en el sumo bien, en la bienaventuranza perdurable: la gracia derivada del bautismo.

Con gran habilidad argumentativa Cartagena va a mostrar la efectiva realidad de ese progreso moral mediante el ejemplo de tres mujeres, escogidas como testimonio egregio de la virtud propia de la naturaleza femenina, la castidad. Lucrecia, Susana y la reina de Castilla Berenguela. Las dos primeras defendieron de modo admirable su honestidad frente a las solicitaciones y a la violencia con que depravados varones querían quebrantarla. Mas era evidente la superioridad de la matrona veterotestamental sobre la romana. Salió aquélla victoriosa del trance y, por tanto, no hubo de recurrir a expeditivas medidas para restaurar su honorabilidad -0 , mejor, rehuir el oprobio- como Lucrecia, deshonrada por Sexto Tarquinio. Así, su suicidio constituía en realidad un demérito, por más que se le reconociera calidad heroica.

Don Alfonso, tal vez movido por el reconocimiento casi universal de la índole virtuosa de tal proceder, se siente obli-

39 Boccaccio 2010, 61.

40 "Set et racioni consonum putaui ut aliud par intersererem ex lege Scripture receptum, ut inter illos qui sub lege nature et gracie vixeru(n)t, isti sedem mediam teneant, ut tribus legibus, quas nature, Scripture ac Gracie uocamus, tria paria celebrium hominum, quos comunis vox populi ystoriarumq(ue) testimonia laudabiles reddunt honestis exemplis respondeant» (Duodenarium, 398).

41 Cartagena 1927, 369. En esta obra desarrolla el prelado burgalés con rigurosa perspectiva histórica la idea que en el Duodenarium se presenta más bien como intuición. Dicha concepción es, en última instancia, deudora de las consideraciones de Santo Tomás sobre los diferentes tipos de leyes y la relación de complementariedad entre la natural y la escrita (cfr. Summa Theologiae, $I^{\mathrm{a}}-\mathrm{II}^{\mathrm{ae}}, \mathrm{q} .94$, a. 5). gado a hacer las oportunas precisiones. De este modo, condena el suicidio que quedara consagrado como manifestación de heroísmo y había suscitado la admiración de los más entusiastas valedores de la ejemplaridad de los antiguos. ${ }^{42}$ Y no solo desde los presupuestos de la moral cristiana, sino conforme a los principios de la razón natural, ${ }^{43}$ el suicidio, aun cuando motivado para evitar la ignominia, es censurable, pues es contrario a la fortaleza de ánimo, ya que revela debilidad, incapacidad de soportar las adversidades, y a la justicia, ya que se comete injusticia contra uno mismo. Para este último extremo, Cartagena recurre a la ciencia jurídica, obviando así la naturaleza esencialmente transitiva de la justicia, virtud dirigida hacia otra persona mediante la ficción jurídica de que la parte sensitiva atenta contra la parte racional de la persona, por analogía con la calificación de irregular que los civilistas daban a quien se automutilaba. ${ }^{44}$

Mas la censura no estaba formulada sin paliativos, pues, siempre ecuánime, reconoce que no solo los antiguos lo han alabado en tal situación, sino que algunos cristianos se han mostrado comprensivos. A su vez, reconoce que la carencia de las leyes de la Escritura y de la Gracia justificaría la comprensión de una acción que, en última instancia, estaba motivada por una aspiración legítima, la fama. Pero, aun así, valorado el suicidio desde los principios de la moral natural, se revelaba censurable, pues no cabía atribuir fortaleza de ánimo a lo que en realidad era una huida de las aflicciones de la vida.

Las sinuosidades de la argumentación de Cartagena son sumamente reveladoras del equilibrio que se esfuerza en mantener entre la admiración hacia el legado de la Antigüedad, que ostenta una auctoritas asentada en la excelencia alcanzada por medio de la razón natural, y la ortodoxia religiosa. Ahora bien, tal vez no carezca de significación la forma en que se refiere a sus fundamentos: la venida del Redentor y la luz del Evangelio. ${ }^{45}$ La acción redentora del Salvador y el testimonio de su mensaje, que se erige en ley. La elección de esta forma («Redentor») entre los nombres de Cristo ${ }^{46}$ no es casual: al destacar el efecto salvífico sobre la humanidad el prelado burgalés estaba, de algún modo, realzando su carácter universal superador de cualquier división en el género humano, concebido así en esencial unidad. En vísperas de los movimientos anti-conversos que consagrarían la discriminación social de los cristianos nuevos, tales palabras debían tener especial significación.

42 Como pone de manifiesto Boccaccio $(2010,205)$ quien se acoge a la terminología de la casuística de la moral cristiana, poniéndola anacrónicamente en boca de la matrona romana: "Yo me absuelvo del pecado pero no me libro de la pena...». Esto es, Lucrecia recurre a la distinción entre mal de culpa y mal de pena, formulada por Santo Tomás: «... malum culpae consistit in operari, malum autem poenae in hoc quod est pati..." (Questiones disputatae, De malo, q. 1, a. 5, co.). La intensa inspiración pagana de la obra de Boccaccio no dejaría de suscitar críticas entre los lectores hispanos (Alvar 2001, 345).

43 En este punto, el obispo de Burgos reitera los argumentos esgrimidos en las glosas a su versión castellana de De providentia de Séneca. Para la realidad del suicidio en la Edad Media véase Schmitt 1976. Para las discusiones teológicas y jurídicas, Andrés 2015, 147-196.

44 Duodenarium, 412.

45 «... cum illi, ante Redemptoris nostri aduentum exorti, nondum luce euangelice legis recepta summo appetitu fame ducerentur..." (Duodenarium, 412).

46 Para la tradición de la teoría de los nomina Christi véase Curtius 1960. 
Y sin embargo, sobre la solemne profesión de ortodoxia, ${ }^{47}$ don Alfonso exhibe una benévola comprensión hacia la axiología de los antiguos. No condena terminantemente el suicidio, sino que exhorta a una connivente estimación. ${ }^{48}$ Aun cuando los argumentos esgrimidos en el Duodenarium ante el suicidio heroico son idénticos a los que ofreciera en sus glosas a De la providençia de Dios, se constata, no obstante, una cierta diferencia de tono: la que marca el paso hacia una estimación más meditada y profunda del legado literario y doctrinal de la Antigüedad, a la que no sería ajena la intensa experiencia cultural del concilio de Basilea. Esa mirada comprensiva hacia los valores paganos, que elude el rigor excesivo, constituye un documento precioso de unas actitudes de tolerancia cultural - de la que podría derivarse la religiosa-, que habrían de verse reducidas a una suerte de marginalidad en la España que iba a consagrar la discriminación de los conversos y a contemplar el establecimiento de la Inquisición.

Tal vez no sea mera casualidad que precisamente en este diálogo se sitúe una observación sobre la vida conventual que podría considerarse crítica tácita. Al ponderar la templanza de Lucrecia, Catón aduce la proximidad de la tentación para realzarla. Y para corroborar su efecto, pone el ejemplo de clausuras y otras honestas congregaciones, que, por el alejamiento de tentadores peligros, garantizaban la honestidad. Es de notar que la observación se extiende tanto a mujeres, objeto de sus consideraciones, como a varones. ¿Acaso no estaría sugiriendo una suerte de déficit de templanza en quienes habían de huir de los peligros de mundo para mantener una honestidad íntegra?

La superioridad de las mujeres que fundamentan su virtud en los principios de las Leyes de la Escritura y de la Gracia sobre las gentiles no solo se muestra a través de la presentación de los casos aducidos de modo ejemplar, sino mediante su explícita valoración: tras la confrontación de las parejas gentiles y de la Ley de la Escritura, don Alfonso exhorta a las matronas católicas a seguir el ejemplo de Susana antes que el de Lucrecia. ${ }^{49}$ La tercera mujer virtuosa, la reina Berenguela de Castilla, no culmina satisfactoriamente la serie de progreso moral sugerida, dada su limitada virtualidad ejemplar, como el propio Cartagena se cuida de advertir. ${ }^{50}$

\subsection{La emulación femenil de las virtudes viriles}

Una vez declarada la esencial heterogeneidad de las naturalezas masculina y femenina, la elección de los ejemplos de excelencia moral de ambos sexos revela la intención de ensayar un planteamiento que la eludiese, mediante la búsqueda de un denominador común en cada una de las parejas virtuosas convocadas que permitiera la

47 Don Alfonso insiste en la incompatibilidad del heroísmo de Lucrecia con la verdad católica: «... imitari tamen non decet catolica veritati inieccioni manuum sanctissime resistente» (Duodenarium, 446). Lo cual contrasta con el reconocimiento pleno, sin censura alguna, de la calidad virtuosa del suicidio de Lucrecia que plantearía Luna 2009, 243-257.

48 "Suficiat nobis illos ut gentiles conniuenti oculo inspectare, licet districto rigore actus eorum non examinemus» (Duodenarium, 414).

49 Duodenarium, 430.

50 Duodenarium, 446. comparación. Para la pagana, eligió el suicidio heroico, ya que fue lo que consagró la fama de la mujer más célebre de la Antigüedad. ${ }^{51}$ De ahí que a Lucrecia se le uniera Catón el Joven: muy significativamente se les asignan los epítetos que definen las virtudes propias de su sexo. ${ }^{52}$ Pero precisamente el suicidio, para don Alfonso no heroico sino censurable, permitiría mostrar la superioridad de la matrona veterotestamental, que vendría a determinar el progreso moral de la Ley de la Escritura sobre la ética de los paganos. De hecho, quien elogia la expeditiva restauración de la honra de Lucrecia es un varón pagano igualmente ilustre, Catón el Joven, a quien Cartagena viene a hacer autorizado portavoz de los valores morales de la Antigüedad.

La segunda pareja, Susana y José, comparten una castidad para cuya defensa hubieron de exhibir una gran fortaleza de ánimo. El prelado burgalés, por boca de José, presenta el tesón indoblegable de Susana frente a las amenazas de los lascivos ancianos como expresión conspicua de fortaleza de ánimo, virtud varonil por excelencia. A su vez, José resulta admirable por la castidad mostrada ante la mujer de Putifar, por una virtud esencialmente femenina. Muy significativamente, el elogio de José se alza, antes que sobre la fortaleza de ánimo, sobre su capacidad para resistir los impulsos de la concupiscencia propia de un varón joven. ${ }^{53}$ De este modo, se invierten las excelencias en las virtudes correspondientes a los sexos, de manera que el mérito de la mujer recae sobre todo en la fortaleza, en tanto que el del hombre, en la castidad. Así, mediante el testimonio de la historia, quedaba demostrado que, por encima de los condicionamientos naturales, mujeres y hombres podían poseer en grado excelso las virtudes propias del sexo contrario. Y ahí tal vez haya que identificar la genuina opinión de don Alfonso en el debate sobre la mujer: ambos sexos son admirables cuando cultivan la virtud, ${ }^{54}$ de lo que se inferiría la futilidad de su rivalidad.

La tercera pareja viene a constituir un remate imperfecto de la evolución sugerida en los tres estadios propuestos. La elección de una pareja de la realeza castellana imprimía un sesgo político al debate sobre sexos. Berenguela y Fernando III, reyes preclaros de un pasado reciente - cuya virtualidad ejemplar le era especialmente cara a don Alfonso-, van a encarnar las virtudes regias ${ }^{55}$ conforme a su naturaleza femínea y viril respectivamente. Así, en el elogio de Berenguela la prudencia presenta una relevancia mayor que la castidad: Fernando, en cuya boca se pone el panegírico de su madre, despacha la ponderación de la castidad como virtud que se da por supuesta en una matrona honesta,

51 Del interés que suscitó la figura de Lucrecia en la Castilla del Cuatrocientos ofrecen datos sumamente valiosos González Rolán y Saquero Suárez-Somonte 2014.

52 «... Casta Lucrecia et fortissimus Cato» (Duodenarium, 398).

53 De hecho, al ponderarse los méritos de José, se antepone la resistencia a los impulsos naturales de la carne a la fortaleza de ánimo: «Set tu non libidinis impulsu, qui iuueniles animos mouet, non fauoris appetitu, quem in domo ampliorem habuisses, non carceris aut mortis timore, quos contempta domina inminere uidebas purum animum cum corporis integritate seruasti» (Duodenarium, 418).

54 «Set illas solas [= virtutes] tangere uolui ex quibus quasi adinvicem proporcionati videntur, ut utrumque sexum cum mundissime uiuit admirabilem esse cognoscas» (Duodenarium, 426).

55 Que desarrolla a propósito de la tercera cuestión (Fernández Gallardo y Jiménez Calvente 2015, 81-86). 
para centrarse en otras cualidades propias de la realeza, ${ }^{56}$ entre las que destaca la prudencia, virtud especialmente meritoria en el ejercicio de responsabilidades de gobierno, y la liberalidad. ${ }^{57}$ A su vez, de Fernando se destacan sus afanes conquistadores: no satisfecho con haber unido bajo un solo cetro los reinos de Castilla y León, se empeñó en ensanchar sus dominios combatiendo a los enemigos de la fe, ganando así para la cristiandad ciudades como Jaén, Córdoba, Murcia y, sobre todo, Sevilla. ${ }^{58}$ Extraña la omisión de la referencia explícita a la castidad, ${ }^{59}$ especialmente pertinente en un debate de tal suerte, sobre todo cuando se había elogiado en el varón correspondiente a la Ley de la Escritura: solo se alude a la evitación de la molicie, comprensible en un rey joven. El debate sobre la naturaleza virtuosa de hombres y mujeres se desplaza hacia la reflexión sobre las virtudes regias, de entre las cuales la pareja de reyes castellanos representa en grado sumo prudencia y liberalidad (Berenguela) y fortaleza de ánimo (Fernando III).

El cotejo de virtudes de hombres y mujeres preclaros pone de manifiesto una estrategia argumentativa orientada a la emulación femenil de la excelencia masculina. Una vez declarada que la virtud propia de la naturaleza viril es la fortaleza de ánimo, don Alfonso mostraría en qué medida las féminas, a quienes, siguiendo la communis opinio, considera blandas de ánimo y débiles de cuerpo conforme a los dictados de la naturaleza, que nadie en su sano juicio se atrevería a cuestionar, ${ }^{60}$ son capaces de ejercerla de modo parangonable a los varones. Este es el argumento clave para sustentar la emulación femenina de las virtudes viriles. Tanto Lucrecia como Susana fueron capaces de superar el temor a la muerte, la piedra de toque de la verdadera fortaleza de ánimo: una suicidándose, la otra arrostrando el riesgo de una muerte terrible por lapidación. Por boca de José, Cartagena sostiene que la fortaleza mostrada por Susana superó la propia de los hombres. Así, en dos ocasiones se refiere explícitamente a la emulación de la virtud viril, ${ }^{61}$ con lo que se afirmaba tácitamente que la mujer virtuosa podría superar al varón.

56 «Nam ut comunia transseam, que honestarum feminarum sunt virginitatem usque ad talamum custodire, mariti torum inviolatum seruare, alia in te singularissima claruerunt..." (Duodenarium, 432).

57 «Set quid de prudencia dicam? Nam licet multe ex honestis matronis sint que domestica et familiaria prudentissime regant, magnam tamen rem publicam paucissime forent que prudenter ea grauitate qua decet gubernare sciuissent. [...] Nedum enim feminas set et liberalissimos viros liberalitatis magnitudine transcendisti» (Duodenarium, 434). En este punto, don Alfonso se hacía eco de la tradición panegírica de Berenguela, en la que desde los primeros testimonios historiográficos se destacaron las virtudes propias de la actividad gubernativa (véase al respecto el cumplido análisis de Salvador Martínez 2012, 789-802; asimismo, Bianchini 2012, 14-16).

58 Duodenarium, 438.

59 Virtud reconocida en una obra patrocinada por el propio Fernando III y perteneciente al género de los espejos de príncipes, el Libro de los doze sabios (Walsh 1975, 192).

60 «... femine molliciem animi ac corporis inbellicitatem, ut sibi congruas, non negant, quia non vicium personarum, set nature proprietas hec est. Naturam autem inproperare nullus mente sanus temptabit» (Duodenarium, 390).

61 «Non solum ergo penam lapidum, que corda virilia terreret, set nec infamiam falso obiectam uere innocentie pretulisti, malens innocenter mori quam nocens viuere. [...] Quis vnquam, oro, virilis actus hanc tuam muliebrem virtutem superauit?» (Duodenarium, 414, 416).

\section{LA MUJER Y EL MATRIMONIO}

La profunda inspiración ética del quehacer intelectual de Alfonso de Cartagena está en la base del desarrollo de unas reflexiones sobre el papel de la mujer en el matrimonio: sus móviles y su función, como si encontrara frívolo el debate sobre sexos y se propusiera aportar alguna utilidad a las consideraciones sobre la índole virtuosa de la mujer, más allá de la emulación de la excelencia varonil.

El punto de partida es la refutación que hace José de la falta de mérito que encontraba Susana en rechazar las solicitaciones de unos viejos repulsivos. José alega que hay mujeres que se unen a hombres poderosos aunque feos para gozar de su prestigio, como las concubinas de los reyes, ${ }^{62}$ para, a continuación, enumerar los motivos de la mujer honesta para acceder al matrimonio.

\subsection{Amor y sexualidad}

A la mujer honesta han de atraerle las virtudes, poder y linaje del hombre que ha de ser su marido. ${ }^{63}$ Es de notar que las cualidades del esposo ofrecen, como devuelta por un espejo, la imagen de la doncella casadera ideal, tal y como quedara consagrada por la tradición que partiendo de la literatura patrística se mantenía vigorosa en las letras castellanas del siglo XV, como pone de manifiesto La Celestina, cuando Pleberio enumera la consabida serie de virtudes que adornaban a Melibea: discreción y honestidad, hermosura, linaje y riqueza. ${ }^{64} \mathrm{~A}$ su vez, la finalidad del matrimonio no es otra que engendrar una prole. ${ }^{65} \mathrm{He}$ aquí expuesta de manera descarnada la realidad de la institución matrimonial en el Medievo: mero espacio de alianzas familiares en que los afectos están no ya ausentes, sino diríase que proscritos. Desde la amplia perspectiva de la evolución de las estructuras de parentesco, el papel axial de la mujer como mecanismo de reproducción del linaje y, por tanto, el reconocimiento de su importancia son la consecuencia de la consagración del principio de verticalidad, que se impuso sobre el papel desempeñado por los parientes colaterales, que determinaría el reforzamiento de la posición de la mujer casada. ${ }^{66}$

El afecto en la pareja, concebido como mero apetito físico, quedaba no ya excluido de las consideraciones morales del matrimonio, sino estigmatizado bajo la figura de lujuria. La libido era para Cartagena una motivación impropia de una matrona honesta, opuesta al imperativo de reproducción de la estirpe que ha de moverla. ${ }^{67}$ Conforme a la doctrina ética de inspiración aristotélica, la libido definía el ámbito de ese amor que constituye la más vehemente de las pasiones. ${ }^{68}$ Pertenece, por tanto, al alma sensitiva, no a la racional, y es, por ende, común a los demás animales.

\footnotetext{
62 Duodenarium, 420.

63 "Splendida namque matrimonia deformium virorum, qui virtutum claritate et potencie ac generis altitudine pollent, apetere honestarum matronarum est...» (Duodenarium, 420).

64 La Celestina, XVI (Rojas 2000, 294-295).

65 Duodenarium, 420.

66 Otis-Cour 2000, 14.

67 «... nupcias non libidinis causa, sed procreandae prolis conficiunt [= matronas honestas]» (Duodenarium, 420).

68 Así reza la segunda de las propiedades que el Tostado distingue en el amor: «... inter caeteras pasiones nulla impetuosiorem esse amore, quo ad libidinem provocamur...» (apud Cátedra 1989, 33).
} 
Cartagena formuló netamente la naturaleza de este amor en una de las glosas de sus traducciones senequistas: «Ay un amor q(ue) es pasió(n) (et) acto de la sensualidad humana (et) está en aq(ue)lla p(ar)te del o(m)bre q(ue) se llama co(n)cupisçible (et) no en la p(ar)te de la razón...». ${ }^{69}$

El contexto en que figura la índole pasional del sentimiento que hay que excluir de la motivación honesta del matrimonio viene a confirmar su adscripción a la parte concupiscible, no racional del ser humano, pues a continuación se justifica la delegación del consentimiento de la doncella casadera en sus padres: para que éste no se halle determinado por la pasión, sino por la razón, que en los padres no se ve alterada.

Por tanto, la sexualidad, elemento ineludible de la esencial finalidad genésica del matrimonio, quedaba relegada a realidad marginal: no tenía lugar reconocido en la reflexión ética sobre la institución matrimonial.

Corolario de la exclusión de la relación física entre los cónyuges de la ética del matrimonio era la del amor como sentimiento integrador de la pulsión erótica. De ahí que el vínculo conyugal no se considerara como el marco adecuado para la experiencia amorosa. En este punto, Cartagena venía a coincidir con la doctrina que al respecto estableciera Graciano, uno de los pilares básicos del Derecho Canónico: prevención y rechazo de toda manifestación de la sexualidad que no estuviera exclusivamente orientada a la procreación. En su Decretum (ca. 1140), Graciano, basándose en la autoridad de san Jerónimo, llegaba a considerar al marido que amaba con excesiva pasión a su mujer como un adúltero. ${ }^{70}$ Lo que recriminaba el severo canonista era una sexualidad no confinada en la mera función reproductora y que se desbordaba en los ámbitos de la pasión amorosa. Atribuye al matrimonio una función cívica decisiva, oponiendo la responsabilidad del marido, comprometido con la república y el género humano, a la del amante capaz de poner en peligro la gestación por su incontinencia. ${ }^{71}$ La justa medida del ejercicio de la sexualidad conyugal, su única justificación, venía determinada por su subordinación a la procreación, por lo que toda práctica no encaminada a tal fin era considerada un exceso, un abuso, ${ }^{72}$ que, al desbordar los límites de la licitud matrimonial, podía lógicamente asimilarse al adulterio. La sexualidad como manifestación del gozo amoroso estaba así condenada como práctica ilícita en el

\footnotetext{
69 Cartagena 1491: sig. tip. I iiii (2) ro, glosa Sepas amar.

70 "Nihil foedius quam uxorem amare quasi adulteram» (Decretum, C.32 q.4 c.5 = Graciano 1861, col. 1480). Al considerar la prevención de los severos canonistas hacia el sexo, hacia la tentación de la mujer, en definitiva, se impone oportunamente la reflexión de Duby acerca de aquellos monjes que obviaban en el culto a la Magdalena su condición de prostituta: «... l'obsession de la souillure sexuelle, [...] l'inquiétude devant la femme épargnaient quelque peu ces hommes, offerts touts enfants au monastère, qui n'en étaient jamais sortis, demeurés vierges par conséquent...» (Duby 1995, 52).

71 «Certe, qui dicunt se causa reipublicae et generis humani uxoribus jungi, et filios procreare, imitentur saltem pecudes, et postquam venter uxoris intumuerit, non perdant filios, nec amatores se uxoribus exhibeant, sed maritos» (Decretum, C.32 q.4 c.5 = Graciano 1861, col. 1480).

72 En términos tajantes y categóricos formuló tal doctrina san Agustín: "Copulatio itaque maris et feminae generandi causa, bonum est naturale nuptiarum: sed isto bono male utitur, qui bestialiter utitur, ut sit ejus intentio in voluptate libidinis, non in voluntate propaginis» (Agustín de Hipona 1865, col. 415).
}

matrimonio. Don Alfonso, eruditísimo jurista, no sería ajeno a los condicionamientos teológicos y canonísticos sobre la estimación del papel de la sexualidad matrimonial. Ahora bien, conviene tener en cuenta que ésta no era la doctrina exclusiva sobre el matrimonio, pues junto al planteamiento rigorista, se desarrolló una línea de pensamiento que, sensible a la concepción aristotélica de la naturaleza y a las aportaciones de la ciencia médica, reconocía el sexo como una realidad que formaba parte del orden natural creado por Dios y, por tanto, había que aceptar. ${ }^{73}$ Cartagena se revela en este punto sumamente conservador, identificándose con las posiciones más rigoristas.

Así, presenta como móvil impropio de una joven honesta en la elección de esposo la "pasión carnal». ${ }^{74}$ Mas debía de tener un amplio concepto de la realidad designada con tal marbete, pues bajo éste incluía el simple deseo de que el marido fuera un varón agraciado, lo cual es expeditivamente recriminado como contrario a los imperativos de la mujer honesta. ${ }^{75}$ El prelado burgalés revela un rigorismo extremo con relación a la estimación del deseo físico entre los cónyuges. Ni la menor concesión a la dimensión afectiva de la convivencia conyugal; tan solo la amenaza de la "pasión», que mancilla inexorablemente la honra de la doncella casadera.

En este punto se evidencia cómo a través de los ditirambos cruzados por la pareja veterotestamental se expresa sobre todo el jurista, a cuya mente acuden las más severas razones de la canonística, antes que el lector de san Pablo, que exhortaba a la contemporización del deseo erótico por la vía del matrimonio.

\subsection{Consentimiento parental}

Cartagena, a pesar de su esfuerzo por mostrar una excelencia femenina parangonable con las virtudes propiamente viriles, debía de tener un concepto más bien pobre de la joven casadera, a la que consideraba inmadura y sin la autonomía moral suficiente como para tomar una decisión honesta en la elección de esposo. Tal es la justificación de la necesidad de que sean los padres quienes elijan al marido adecuado para sus hijas: evitar que la «pasión carnal» interfiriera en lo que se consideraba, conforme a la doctrina del Decretum de Graciano, negocio que redundaba en el bien de la república. ${ }^{76}$

En este punto se manifiesta el docto jurista que se ve obligado a hacer compatibles una práctica, que reconoce universal, el consentimiento parental, con la libertad de elección de los cónyuges que la doctrina canónica había consagrado. En efecto, para la Iglesia, el pilar fundamental del vínculo matrimonial es el libre acuerdo de los cónyuges,

\footnotetext{
73 Otis-Cour 2000, 92-97.
}

74 «Hinc honeste et laudabiles adolescentule non arbitrio suo, set parentum suorum viros recipiunt ne in earum iudicio aliquem forssam carnalis passionis impulsum misceri quispiam suspicari valeret...» (Duodenarium, 420).

75 «... vt clariorem [prolem] faciant clariorum virorum, non pulcriorum connubia querunt [= mujeres honestas]» (Duodenarium, 420).

76 "Hinc honeste et laudabiles adolescentule non arbitrio suo, set parentum suorum viros recipiunt ne in earum iudicio aliquem forssam carnalis passionis impulsum misceri quispiam suspicari valeret, qui a parentibus abest, cum de filiarum aut nepotum coniunccione pertranctant» (Duodenarium, 420). 
tal y como quedara formulado en las Decretales de Gregorio IX, que, a su vez, recoge la formulación del principio romanista sobre el matrimonio. ${ }^{77}$ Mas la ineludible realidad social de la intervención de los padres en la elección de esposo exigía el reconocimiento de su compatibilidad con el principio canónico irrefragable. Don Alfonso recurre hábilmente a una componenda consistente en sostener, por un lado, la necesidad de que la joven casadera delegue en el juicio de sus progenitores para evitar sospechas de libidinosas motivaciones en la elección de marido, a la vez que invoca su opinión, pero solo al final de las negociaciones, aceptando lo acordado por los padres. Se reduce al mínimo la capacidad de decisión de la mujer; su consentimiento, ineludible según la doctrina de la Iglesia sobre el matrimonio, en realidad viene a ser confirmación de la elección paterna.

Cartagena refleja una posición maximalista con respecto a la potestad de los padres, reduciendo el papel de la mujer a un mero cumplimiento formal de la inexcusable norma eclesiástica. En este punto el jurista con sólida formación canonista se revela más afecto a la tradición jurídica vernácula que a los principios del Derecho Común, en la medida en que el principio esencial del matrimonio conforme a la doctrina de la Iglesia, el consentimiento de los contrayentes, quedaba subordinado a la práctica real, el papel esencial de los padres, ${ }^{78}$ que, a su vez, era reconocido en las leyes vernáculas hispanas.

Sin embargo, con respecto al consentimiento parental, don Alfonso reconoce la potestad de la madre, en lugar de limitarla al padre, ${ }^{79}$ esto es, admite para la mujer un cierto protagonismo, al menos en los asuntos familiares, lo que no dejaba de contrastar con la opinión corriente en la época, que restringía la responsabilidad de la elección del esposo al padre de la doncella casadera, como pone de manifiesto un texto literario que había de mostrarse especialmente sensible a estas cuestiones, máxime siendo jurista su autor. ${ }^{80}$

77 «Matrimonio solo consensu contrahitur...» (Liber extra 4.1.1) Cfr.: «Nuptias non concubitus, sed consensus facit» (Digestum 50.17.30). La herencia romanista, que enfatizaba el acuerdo, el consenso, como fundamento del matrimonio, sería completada por la idea cristiana de unión en una sola carne, inspirada en el Génesis, que destacaría, a su vez, el papel del coito en la unión conyugal (Reynolds 1994, 32). Por otra parte, en la identificación del sujeto del consentimiento hubo una vacilación entre los padres o los propios contrayentes. Se impondría finalmente esta última opción, sostenida por la autoridad de un Pedro Lombardo (Otis-Cour 2000, 106). Se ha visto en el conflicto entre consentimiento de los padres y el de los cónyuges transposición del que se daba entre la doctrina eclesiástica y los valores de la sociedad laica (Goody 2009, 147).

78 Aunque hay que tener en cuenta que también los canonistas avalaban la intervención de los padres. Graciano había establecido el consentimiento paterno como requisito del matrimonio legítimo: «... paternus consensus desideratur in nuptiis, nec sine eo legitimae nuptiae habeantur...» (Decretum, C.32 q.2 c.12 = Graciano 1861, col. 1473).

79 Pues se refiere a «parentum suorum» (Duodenarium, 420).

80 «Pero como esto sea oficio [= elección de marido] de los padres y muy ajeno a las mujeres...» (Celestina, XVI, p. 295). Las Partidas, cuya doctrina matrimonial, por otra parte, acoge el principio de libre consentimiento de los contrayentes por influencia del Derecho Canónico, se refieren única y exclusivamente al padre, en singular en las disposiciones que regulan la intervención de los padres en los desposorios [Las siete Partidas 1807: 9-10 (Partida IV, tít. I, ley X)]. El Fuero Real, en cambio, contemplaba la participación de la madre en el consentimiento [Fuero Real 1836, 64-65 (lib. III, tít. I, ley II, V, VI)]. Para la realidad efectiva de esta práctica, referida a la nobleza castellana, véase Beceiro Pita y Córdoba de la Llave 1990, 128-142.
En la medida en que las observaciones relativas al matrimonio son en cierto modo una digresión en el marco de la estructura dialógica de esta sección del Duodenarium, se revelan como inequívocamente genuinas del pensamiento del autor. $Y$ en este punto, Alfonso de Cartagena pone de manifiesto unas actitudes que cabe calificar de rigoristas con respecto a la institución matrimonial. En primer lugar, su valoración de la sexualidad conyugal se sitúa en la órbita de la estimación más restrictiva, la que representara el canonista Huguccio († 1210), según la cual toda actividad sexual no estaba nunca, ni siquiera dentro del matrimonio, libre de pecado. De ahí una consideración de la unión conyugal como mero mecanismo reproductor del linaje, carente de implicaciones afectivas entre los cónyuges. A su vez, la argumentación de la compatibilidad entre el consentimiento de los contrayentes y la potestad parental en la elección de esposo revelan un planteamiento netamente restrictivo de la libertad de elección de la mujer.

\section{LA MUJER EN EL MATRIMONIO}

Una vez consignada la conclusión, que, tras la serie de diálogos, deja muy hábilmente al arbitrio del lector, Alfonso de Cartagena no debió de sentirse enteramente satisfecho con su aportación al debate sobre sexos. Estimaría demasiado lejana de la experiencia cotidiana la excelencia que en las virtudes femeniles alcanzaron Lucrecia, Susana y la reina Berenguela; lo artificioso, en definitiva, de un debate de naturaleza esencialmente literaria, libresca. De ahí que decidiera completar su vindicación de la virtud femenina no en el caso extremo, excelso, de la heroicidad martirial, sino en la normalidad de la realidad cotidiana, en el marco de la vida matrimonial. Más que una perspectiva realista, ineludible si pretendía una utilidad didáctica en su escrito, habría que ver un anticipo de la nueva valoración del matrimonio como ámbito de plena realización del cristiano, expresión de la secularización de la piedad que llevaría a cabo Erasmo de Rotterdam en el siglo siguiente, frente a los valedores coetáneos del retiro eremítico. ${ }^{81}$

Y para ello se acoge a la irrefragable autoridad de la $\mathrm{Bi}$ blia, el libro de los Proverbios, que contienen el elogio de la buena esposa (Proverbia 31), que glosará en sentido moral. ${ }^{82}$ La elección de esta modalidad exegética obedece a la finalidad propuesta. El sesgo ético que don Alfonso se propone imprimir a su aportación al debate cortesano exigía la perspectiva práctica que posee el sentido tropológico. En efecto, conforme a la doctrina de los cuatro sentidos escriturarios, el moral se aplicaba a la vida práctica. El célebre dístico de san Agustín de Dinamarca († 1285) así lo establecía, en la forma aforística que tuvo universal recepción:

Littera gesta docet, quid credas allegoria, moralis quid agas, quo tendas anagogia.

81 Fernández Gallardo 2012b, 224. Aunque conviene tener en cuenta que no le sería extraña a don Alfonso la corriente de opinión que exaltaba el ordo conjugatorum, que tuvo especial desarrollo en el siglo XIII (Le Bras 1968, 193).

82 "Que si vis pedetentim et aliquantulum late more illorum qui Sacre Scripture textum ad morales doctrinas adaptant prosequamur...» (Duodenarium, 448). 
El padre de Cartagena, don Pablo de Santa María, se lo recordaría en el prólogo de sus Additiones ad Postillam Lyrae, ${ }^{83}$ obra que precisamente le dedicó, ofreciéndole en dicha pieza liminar un breve tratado de hermenéutica bíblica, con rigurosa demostración de la superioridad de los denominados "sensus spitiruales» sobre el "sensus litteralis». Así, tras sugerir el alcance práctico de la lectura del texto bíblico, Cartagena traslada el debate sobre la mujer - pues, a fin de cuentas, la polémica sobre sexos ha derivado en la vindicación de las virtudes femeniles- del juego cortesano a la vida familiar. Diríase que viene a ser un complemento de su estimación del papel de la mujer en el matrimonio: a la función genésica, la propagación del linaje, ya destacada, viene a añadir su función en el hogar.

Al hilo de la exégesis bíblica va perfilando el ideal de la mujer casada, un curioso anticipo, aunque desde principios hermenéuticos diferentes, de una de las cumbres de la prosa quinientista, La perfecta casada de Fray Luis de León. ${ }^{84}$ Como cierre de la ceñida lectura del texto veterotestamental, ofrece un compendio de las virtudes de la matrona ideal, selección que viene a constituir la genuina concepción que tenía don Alfonso de la función de la mujer en el matrimonio: devoción, liberalidad con los pobres, castidad y diligencia en el gobierno de la casa. ${ }^{85}$

El orden de la enumeración no refleja jerarquía, pues la castidad, virtud femenina por antonomasia, ocupa en realidad una posición axial. Ahora se identifica con pureza corporal al vincularse con la fidelidad conyugal, de manera que viene a representar una suerte de patrimonio del marido. Don Alfonso parte del sintagma «Mulierem fortem» del texto bíblico, cuya interpretación tropológica elude, ${ }^{86}$ para, manteniendo la estricta literalidad, construir el panegírico de la perfecta casada. Así, sugiriendo lo impropio del adjetivo "fortis» referido a la mujer, pasa al siguiente versículo, que ensalza la fidelidad, que, a su vez, hace pivotar sobre la pudicia conyugal, que se identifica con integridad, pureza corporal, esto es, patrimonio exclusivo del marido. ${ }^{87}$ Se trata del honor conyugal, fundamentado en la fidelidad marital de la esposa, esto es, la vieja idea de la honra según la cual la conducta de la mujer repercutía sobre todo el linaje. ${ }^{88}$ En el lecho conyugal se materializaba así el honor como espacio cuya pureza había que preservar. De modo tácito don Alfonso estaba sugiriendo que el bien más preciado del

83 Con las siguientes variantes: «Littera gesta docet, quid credas allegoria,/ Tropologia quid agas, quid speres anagogia» don Pablo explica así el tercer sentido: «per sensum vero tropologicum [habentur], quae sunt agenda, quod pertinet ad charitatem» (Santa María 1852, col. 38).

84 Fernández Gallardo 2012b, 223.

85 «Ab illa siquidem, ut integre probitatis sit, solum expetimus ut deuota ad Deum pia ad inopes et castitatis acerrima custos solersque rei domestice gubernatrix existat» (Duodenarium, 480).

${ }^{86}$ La exégesis tradicional la había identificado con la Iglesia, como evidencia la Glossa ordinaria (Walafrido Strabo 1852, col. 1114), o con la Sagrada Escritura (Lyra 1481: Ad Proverbia $(31,10)$, glosa Mulierem fortem.

87 «Quid enim - queso- tantam confidenciam viro ad vxorem prebere solet sicuti oberuancia pudicicie coniugalis? Profecto nichil tam excelsum, nichil tam amenum, nichil denique tam vtile mater familias efficere potest, ut mariti sui integrum cor possideat, sicut inviolate thori custodie operam puram dare» (Duodenarium, 450).

88 Véase el estudio clásico de Sánchez-Albornoz 2001, I: 615-662, (especialmente 621-622). hombre es el honor, concebido como consciencia segura de la honorabilidad de la esposa.

La segunda virtud de la matrona excelente es la habilidad en el gobierno y gestión del hogar, en la atención de los asuntos domésticos. La función social de la mujer se desarrolla exclusivamente en el interior del hogar, el ámbito adecuado para que alcancen su plenitud las virtudes femeninas. La reclusión en el hogar es contemplada como preservación de esa pudicia sobre la que reposa el honor conyugal. ${ }^{89}$ Tan estricto es tal imperativo que Cartagena se ve obligado a forzar la letra del texto veterotestamental en que se identifica a la matrona en el ejercicio de su gobierno del hogar con nave mercante (Proverbia 31, 14), transformando espacio en tiempo, el lejano desplazamiento vedado en prudente previsión. ${ }^{90}$

Las restantes virtudes, devoción y solicitud para con los pobres, diríase son más bien inexcusable deuda con el texto bíblico, antes que expresión genuina del ideal femenino de don Alfonso. Y siempre la tensión vigilante de la inflexible observación de la pudicia. Así, advierte de los peligros que acechaban a las amas de casa en la frecuentación de iglesias y santuarios: si la devoción se practicaba en detrimento de las obligaciones domésticas, se incurría en vicio propio de trotacalles. He aquí el tipo literario de la trotaconventos, si no es que esas "vagae vetulae» están tomadas de la realidad social. ${ }^{91}$

Tan decisiva es la determinación ejercida por la castidad sobre el resto de las virtudes femeninas, que quedan excluidas del elenco de cualidades que conforman la excelencia matronal propuesta por Salomón. Así, era de esperar que la recomendación del uso de cobertor y de indumentaria de batista y púrpura (Proverbia 31, 22) se matizara considerablemente: el comentario viene a ser una llamada a la moderación de la exhortación bíblica, siendo contemplado el ornato como tentación de la pudicia de la mujer casada. Solo concede el prelado burgalés la conveniencia del acicalamiento de la esposa en la medida en que se subordina al honor del marido..$^{92}$ En cambio, extraña que quien tanto hiciera por difundir el saber entre la élite nobiliaria mostrara un criterio aún más restrictivo que un misógino

89 «cum hoc congruentissimum feminee honestatis sit raro per publicum evagari et negociaciones extrinssece viris non matronis conueniant» (Duodenarium, 454).

90 Duodenarium, 454.

91 «Nam continue predicacionibus audiendis insistere, altaria frequentare et ad diuersa sanctuaria, domus sue cura neglecta, crebo peregrinando proficisci in coniugatis matronis comendandum non est, quia illud vagarum vetularum, non prudentum ac deuotarum matronarum esse videtur» (Duodenarium, 474). Cfr. Fernández Gallardo 2012b, 227-228. No hay que perder de vista que el Libro de buen amor era disfrutado no solo por el público de juglares, sino por sesudos letrados y escolares, como pone de manifiesto el que una copia de esta obra fuera realizada por Alfonso de Paradinas, colegial de San Bartolomé y luego catedrático de Cánones en Salamanca, hacia 14251430 (Menéndez Pidal 1973). ¿Habrá que ver en la exhortación a la actividad doméstica de la mujer frente a la inmoderada devoción un argumento en pro de la vida activa? Sobre el debate acerca de las relaciones entre las vidas contemplativa y activa en Castilla véase el denso estudio de Valero Moreno 2015b (para la posición Cartagena, pp. 50-54)

92 "Ornatus namque decens absque inani iactancia fuco et ficcione reiectis, non improbabilis in coniugatis feminis est, qui nedum ipsam matronam honestat redditque clariorem, set eciam ipsum virum clarificat» (Duodenarium, 466). 
militante como su coetáneo el Arcipreste de Talavera en lo que respecta a la instrucción de la mujer. A propósito del versículo que permitía avalar la sabiduría de la mujer (Proverbia 31,26), simplemente niega el acceso de las féminas - pero también de buena parte de los hombres - al saber científico como si de un axioma se tratara y reconduce hábilmente la interpretación del texto bíblico a identificar sabiduría con la dócil recepción de los sermones de doctos predicadores. ${ }^{93}$

Cartagena no pierde de vista en ningún momento a quién van dirigidas sus razones. De ahí que el modelo de matrona que va perfilando al hilo del comentario bíblico corresponda al estamento nobiliario. Esa aguda conciencia de las obligaciones estamentales, que constituye uno de los fundamentos de su concepción de la sociedad, se mantiene constantemente tensa, mediante la idea de dignitas y status, que determina el límite de la aplicación de la literalidad bíblica a la matrona noble. Así, las labores textiles, muestra de los trabajos domésticos de la mujer virtuosa, son recomendados con la salvedad impuesta por la «dignidad de las personas», resolviéndose la exhortación al trabajo manual a su tácita delegación en siervos y criadas, mediante sutil interpretación del sintagma «consilio manuum suarum $» .{ }^{94}$

\section{DE LA DISPUTATIO AL DIÁLOGO INTERGENÉRICO}

La cuarta cuestión del Duodenarium es la que presenta una elaboración formal más cuidada. Don Alfonso recurre a un artificio literario para dar respuesta cabal a la pregunta planteada por Pérez de Guzmán. Dejando a un lado la prosa doctrinal que hasta entonces había guiado con propósito magistral el curso de sus razones, decide adentrarse en el ámbito de la ficción mediante la construcción del diálogo, 95 que justifica como estrategia formal que permitía obviar la prolijidad de las fuentes históricas, a la vez que mantener una apariencia de ecuanimidad por cuanto el autor delegaba su voz en la de los personajes intervinientes, a quienes se endosa la responsabilidad de dirimir la cuestión. ${ }^{96}$ El término clave del razonamiento es el verbo "fingamus»,

93 Duodenarium, 474.

94 «Opera quipe muliebria que intra domum aguntur, exprimere voluit, cum lane linique textura exercicium sit matronarum, ut interdum per se, quantum dignitas personarum permittit, sepe seruorum et ancillarum ministerio lanificio ac linificiis intendat. "Consilio enim manuum suarum" operari dicitur quod per laborem seruitorum efficere curat, cum manus mittere dicimur ad illud quod per nostram potenciam operamur» (Duodenarium, 452). En cambio, el huso y la rueca y demás utensilios domésticos formarían poco después parte de la iconografía asociada a la función de la mujer en el hogar, que el nuevo arte del grabado se encargaría de difundir, como ponen de manifiesto los compuestos por el alemán Hans Paur para ilustrar un poema sobre el equipamiento del hogar (ca. 1480-1485). Véase reproducción en Schoh 1986, 96.

95 Véase Fernández Gallardo 2007, 77-82. Ofrece un fino análisis de la estructura dialógica de esta sección del Duodenarium Jiménez Calvente 2015, 139-149.

96 «At quia eorum actus cronice luculentissime narrant, tanquam omnibus notos, referre non libet, set alterum alteri comparare et, ne linguam nostram in eos ponamus, sese ipsi diiudicent. Et fingamus eos ad inuicem colloquentes et quis alium precedere debeat disputantes...» (Duodenarium, 398). Analiza el carácter argumentativo del género dialógico en el marco de la interlocución Vian 2001. cuyo significado - que no tiene que ver con la noción moral de engaño, sino con la idea de composición y creación poética- ${ }^{97}$ queda realzado por compartir el contexto de la referencia a las crónicas, a las que según el propio Cartagena ha de guiar el imperativo de verdad..$^{98}$ La invitación a la ficción a que apunta el subjuntivo con valor exhortativo "fingamus» es expresivo de una inequívoca voluntad de elaboración literaria. ${ }^{99}$

El recurso a uno de los géneros característicos de la literatura humanística ${ }^{100}$ no ha de ser ajeno a la reciente experiencia cultural de don Alfonso en Basilea y su conocimiento de las realizaciones del humanismo. La amistad anudada con los más destacados humanistas, Leonardo Bruni, Poggio Bracciolini, Pier Candido Decembrio, que cultivaron el género dialógico, ya sea en creación original o en traducción del griego, hubo de ser un estímulo decisivo para la adopción de este artificio literario aplicado a un tema que contenía arduas implicaciones doctrinales. No obstante, cuando se vio precisado a poner ejemplos de la práctica de la escritura dialógica (indicación del nombre de los interlocutores) se le vinieron a las mientes no autores clásicos, como $\mathrm{Ci}$ cerón, sino Gregorio Magno y Anselmo de Canterbury, eximios representantes de la literatura cristiana. ${ }^{101} \mathrm{~A}$ su vez, en la medida en que se trataba de debates en que las parejas convocadas contendían sobre la superior excelencia virtuosa del contrario, hubo de imponérsele inevitablemente el modelo del diálogo-disputa, ${ }^{102}$ que su padre, don Pablo de Santa María, había cultivado muy notablemente en una de las cimas de la literatura polémica antijudía, el Scrutinium Scripturarum. ${ }^{103}$ De este modo, la inspiración humanística se materializaba en los añejos esquemas de la disputatio aunque no hay que perder de vista que la conciencia del género dialógico que tenían sus cultores no establecía tan netos lindes entre las distintas tradiciones como alza la crítica moderna, ${ }^{104}$ a la vez que la disputatio fue uno el vehículo de la reflexión sobre la identidad de género más característico del paradigma escolástico-. ${ }^{105}$

Así, por un lado, la terminología utilizada para referirse al molde genérico escogido es reveladora de la adscripción a la tradición del diálogo-disputa, aunque el equilibrio que

97 Fernández Gallardo y Jiménez Calvente 2015, 100.

98 Alfonso de Cartagena, Epistula directa ad Petrum Fernandi de Velasco, apud Lawrance 1979, 54.

99 Fernández Gallardo 2007, 77-78.

100 Kristeller 1974, 5; Marsh 1980.

101 En carta dirigida a Pier Candido Decembrio a propósito de la traducción al latín de La República de Platón: «... sic et alii famosissimi scriptores hoc in dialogis semper obseruant; sic Gregorius, sic Anselmus...» (apud González Rolán, Moreno Hernández y Saquero Suárez-Somonte 2000, 386).

102 Para la concepción del diálogo como disputatio véase Cardelle de Hartmann 2007, 48-50. Constituye ésta la veta más destacada de la tradición medieval del diálogo (Gómez 2000, 41-53).

103 Que tuvo, precisamente, una gran difusión y prestigio en la Basilea conciliar (Lehmann 1941, 273). Véase Fernández Gallardo y Jiménez Calvente 2015, 99.

104 Como pone de manifiesto uno de los más preclaros representantes de la tradición patrística, san Jerónimo, quien al combatir la herejía pelagiana adoptara la forma de diálogo enlazando, consciente de sus raíces clásicas, con la tradición socrática: «... hic liber quem nunc cudere nitimur, Socraticorum consuetudinem servabit, ut ex utraque parte quid dici possit exponat, et magis perspicua veritas fiat, cum posuerit unusquisque quod senserit» (Jerónimo 1883, col. 519).

105 Allen 2002, 68-74. 
define el talante intelectual de don Alfonso le alejara de los agrios extremos polémicos de dicha tradición y optara por una «disputa de guante blanco». ${ }^{106}$ El verbo dialogizare, neologismo que figura en los epígrafes de los capítulos que abren cada uno de los tres diálogos, ${ }^{107}$ viene a hacer referencia al carácter de disputa que éstos presentan, dado que el término dialogus era sinónimo de altercatio, ${ }^{108}$ de la misma manera que dialogista lo fuera de disputator. ${ }^{109} \mathrm{~A}$ su vez, la referencia a las parejas intervinientes como «disputantes» define inequívocamente la naturaleza del diálogo construido, aunque no hay que perder de vista que precisamente los humanistas renovaron la práctica escolar de la disputatio mediante el diálogo. ${ }^{110}$

Mas, por otra parte, se advierte un aire nuevo en estos tres diálogos proveniente de la reciente experiencia humanística de su autor. No solo la prosapia clásica de la primera pareja, evocación de los valores morales de la reverenciada Antigüedad, sino el acusado retoricismo con que se tejen las intervenciones, ${ }^{111}$ a la vez que la presencia de la mujer en papel protagonista ${ }^{112}$-lo que, por otra parte, venía impuesto por la naturaleza del tema-, marcan una cierta distancia con respecto a los debates característicos del Medievo hispano. Ahora bien, todo ello no obsta el que las pláticas de las tres parejas convocadas se hallen más cerca del debate medieval que del diálogo humanístico.

En efecto, los coloquios de Cartagena no atienden ni al marco temporal ni al espacio físico, ${ }^{113}$ esto es, eluden las circunstancias imprescindibles que permiten mantener un mínimo de verosimilitud, más allá de la mera interlocución.

106 Según la acertada caracterización de Jiménez Calvente 2015,
143.
107 Duodenarium, 398, 414, 432. Cartagena utiliza también dicho verbo con el sentido de "escribir en forma de diálogo» en una carta dirigida a Pier Candido Decembrio citada: «... sic Gregorius, sic Anselmus et alii paene innumeri, qui aliquos libros dialogizando scripserunt, hoc diligenter attendere curauerunt» (apud González Rolán, Moreno Hernández y Saquero Suárez-Somonte 2000, 386).

108 Zappala 1989, 46-49. Sin embargo, el Catholicon, al definir el término dialogus, ateniéndose estrictamente a la etimología, destaca el intercambio verbal entre dos: «dualis sermo, sc(ilicet) q(ue) uersat(ur) inter duos, a dia, q(uo)d e(st) duo, et logos, sermo» (Balbus Januensis 1490 , s. v. dialogus, f. $137 \mathrm{v}$-). Este autor asume la doctrina sobre el diálogo de Guillermo de Conches, solo que la desarrolla bajo el término Hermeneuticus (Cardelle 2007, 43).

109 Du Cange 1883-1887, t. III: s. v. dialogista, col. 99a. Esta concepción del diálogo se mantiene vigorosa en pleno Renacimiento, cuando todavía lo define como "manera de disputa» Rodrigo de Espinosa Santayana en su Arte de retórica (1572) (apud Gómez 2000, 17).

110 Cossutta 1984, 150-151.

111 Destacado por Jiménez Calvente 2015, 146.

112 Se ha señalado la esporádica presencia de las mujeres en los diálogos, a pesar de la ausencia de limitaciones sobre la condición social de los interlocutores, aduciéndose la justificación que hiciera san Agustín de la intervención de su madre Mónica en la disputa filosófica de De ordine (Gómez 1988, 25).

113 Jiménez Calvente 2015, 143. El propio Cartagena advierte de la infranqueable distancia temporal que separa a los interlocutores, que solo su voluntad creativa puede superar, «licet illos magna interiacencia temporis diuidat, nostro tamen calami contemplacio congreget» (Duodenarium, p. 414). He aquí un testimonio de la sensibilidad histórica del prelado burgalés, que habrá que poner en la cuenta de su vocación historiográfica. ¿Es solo cronológica la distancia constatada entre ambos personajes o es percibida como heterogeneidad de épocas? Sobre esta cuestión, el sentido del anacronismo, ha reflexionado recientemente Burke 2016, 177-197.
De hecho, solo el uso de la segunda persona, reforzada con los vocativos que abren las intervenciones, ${ }^{114}$ constituye el mínimo artificio que conforma la estructura dialógica, de manera que, sin justificación del encuentro y la conversación de los interlocutores, que, por otra parte, corre a cargo de la voz del autor, que actúa como su presentador, se entra directamente en materia. Ni siquiera breves réplicas que sugieran la espontaneidad de la conversación ${ }^{115}$ - como, por el contrario, se constatan en el Scrutinium Scripturarum, aunque se subordinen, obviamente, a reforzar la argumentación mediante oportunas aclaraciones-. A su vez, la división en capítulos, que coinciden con las intervenciones, superpone un elemento estructurador de los contenidos que sacrifica la verosimilitud dialógica, rompiendo la fluidez del diálogo en aras de la claridad didáctica. ${ }^{116}$

El resultado es, pues, una sucesión de monólogos, que constituyen auténticos discursos encomiásticos. ${ }^{117}$ Pero hay que relativizar tal falta de naturalidad, en la medida en que obras que sí que aspiraban a cierto grado de verosimilitud realista contenían diálogos de análoga índole, amplias peroratas de los interlocutores con un estilo artificioso y retórico, como es el caso de la obra maestra del género, $L a$ Celestina: ${ }^{118}$ y es que la finalidad didáctica entraba inevitablemente en conflicto con el artificio de la ficción conversacional, imponiendo una tensión docente que reduce la espontaneidad propia de la conversación que se pretende fingir.

\section{Conclusión. Aportaciones de Alfonso de Cartagena AL DEBATE SOBRE LA MUJER}

No hubo de dejar indiferentes a los círculos literarios de la Castilla del Cuatrocientos la intervención de Cartagena en el debate sobre la mujer. El enorme prestigio de que gozaba aseguraba no solo su toma en consideración, sino su asunción -se entiende que solo por quienes defendieran la causa de las féminas-. Don Alfonso aportaba en primer lugar una ponderación que servía de lenitivo a la crispación polémica, a los excesos misóginos, reconduciendo así el debate a los cauces del sentido común. Tal fue su primera contribución, una extensa glosa orientada a templar el exabrupto misógino que su dilecto Séneca deslizara en obra

114 Como en el caso de un diálogo que debía de tener en mente don Alfonso, el elaborado por su padre en su Scrutinium Scripturarum. La primera intervención de los dos interlocutores, Saulo y Pablo, se abre con sendas interpelaciones (vocativo precedido de interjección) (Santa María 1591, 105a, 106a).

115 Don Alfonso prescinde, pues, de la «ficción conversacional» —estudiada por Vian 1988-, ofreciendo, en cambio, una sucesión de intervenciones que diríase previamente concertadas.

116 La superposición de la estructura expositiva mediante capítulos al diálogo venía avalada por el ejemplo paterno: en su Scrutinium Scripturarum, don Pablo ajusta el diálogo a la serie de distinctiones y capitula en que se articula la confutación de la caecitas iudaica.

117 Fernández Gallardo y Jiménez Calvente 2015, 100. Se trata de una de las posibilidades del género, en que el propósito didáctico se antepone al artificio literario: «discursos monológicos convertidos artificialmente en diálogos» (Gómez 1988, 19). Cuadra perfectamente a este propósito la expresión acuñada por Unamuno, «monólogos dialogados», paradójica conforme a su temple intelectual, en su relato «Las tijeras» (1889) (Unamuno 2009, 180).

118 En la que se utiliza lo que se ha denominado «diálogo oratorio» (Lida de Malkiel 1962, 108-111). 
por él traducida. Un desarrollo mucho más detallado ofrece la respuesta a la cuestión planteada por Pérez de Guzmán. Tras afirmar la superioridad de la más excelente mujer, la Virgen María, sobre cualquier varón, procede a encuadrar el debate, mostrando la heterogeneidad de la excelencia aretológica de mujeres y hombres. Así, las virtudes propias de la mujer son castidad, modestia, recato. Pero confronta parejas virtuosas para poner de manifiesto que la mujer puede alcanzar también altas cotas de excelencia en virtudes propias del hombre que ostenta responsabilidades de gobierno (fortaleza de ánimo, prudencia, liberalidad).

A su vez, al hilo de tales consideraciones, Cartagena descubre su posición en cuestiones relevantes del matrimonio, como su función, papel de la sexualidad, consentimiento parental, que se revela fuertemente conservadora. Mas al trazar el perfil de la perfecta casada, interesante anticipo de la obra así titulada de Fray Luis de León, descubre una concepción del matrimonio como ámbito de perfección cristiana, en sintonía con las nuevas formas de espiritualidad.

Don Alfonso cuida los aspectos formales: recurre al diálogo, que se revela deudor del diálogo-disputa de la tradición medieval, aunque introduce elementos humanísticos.

\section{FUENTES}

Agustín de Hipona. 1865. De nuptiis et concupiscentia. Ed. J.-P. Migne. PL, t. XLIV: col. 415-474. París: In Via dicta Thibaut.

Aristóteles 1988. Ética Nicomáquea. Trad. J. Pallí Bonet. Madrid: Gredos. Balbus Januensis, J. 1490. Catholicon. Maguncia: Gutenberg (?)

Boccaccio, G. 2010. Mujeres preclaras. Trad. V. Díaz-Corralejo. Madrid: Cátedra.

Cartagena, Alfonso de (trad.) 1491. Cinco libros de Séneca. Sevilla: Ungut-Polono.

Cartagena, Alfonso de 1927. Traslación de las reliquias de Santa Juliana, apud Mateo Escagedo Salmón, Colección Diplomática. Privilegios, escrituras y bulas en pergamino de la Insigne y Real Iglesia Colegial de Santillana. T. II. Santoña: Tipografía Dialco Mnemaen.

Digestum, en Corpus luris Civilis <https://droitromain.univ-grenoblealpes.fr>

Fuero Real. 1836. En Opúsculos legales del rey don Alfonso el Sabio, ed. Real Academia de la Historia, t. II, 3-177. Madrid: Imprenta Real,

Graciano 1861. Decretum, ed. J.-P. Migne, PL, t. CLXXXVII. París: Rue Petit Montrouge.

Jerónimo. 1883. Dialogus adversus Pelagianos. Ed. J.-P. Migne, PL, XXIII: cols. 495-590. París: Apud Garnier Fratres Editores.

Las siete Partidas del rey don Alfonso el Sabio. 1807. T. III. Madrid: Real Academia de la Historia.

Liber extra. En Corpus luris Canonici, ed. Emil L. Richter. 1959, cols. 1-928. Graz: Akademische Druck- u. Verlagsanstalt.

Luna, Álvaro de. 2009. Libro de las virtuosas e claras mujeres. Ed. Julio Vélez-Sainz. Madrid: Cátedra.

Lyra, Nicolaus de. 1481. Biblia cum postillis Nicolai de Lyra. Venecia: Johann von Köln, Nicolaus Genson.

Pérez de Guzmán, Fernán. 1924. Generaciones y semblanzas. Ed. Jesús Domínguez Bordona. Madrid: Espasa-Calpe.

Pulgar, Fernando de 1985. Claros varones de Castilla. Ed. Robert Brian Tate. Madrid: Taurus.

Rojas, Fernando de (y «Antiguo autor») 2000. La Celestina. Ed. F. Rico. Barcelona: Crítica.

Santa María, Pablo de 1852. Additio super utrumque prologum Postillae. ed. J.-P. Migne, PL, t. CXIII: cols. 37-50. París: In Via d'Amboise.

Santa María, Pablo de 1591. Scrutinium Scripturarum. Ed. C. Sanctotis. Burgos: Apud Philippum luntam.
Tomás de Aquino, Summa Theologiae. http://www.corpusthomisticum.org/iopera.html\#OM

Tomás de Aquino, Questiones disputatae. http://www.corpusthomisticum.org/iopera.html\#OM

Torre, Fernando de la. 2009. Libro de las veynte cartas e quistiones y otros versos y prosas. Edición de María José Díez Garretas. Burgos: Instituto Castellano y Leonés de la Lengua.

Walafrido Strabo. 1852. Glossa ordinaria, ed. J.-P. Migne, PL, t. CXIII: cols. 67-1316. París: In Via d’Amboise.

\section{BiBLIOGRAFÍA}

Accorsi, Federica, ed. 2009. Diego de Valera, Defensa de virtuosas mujeres. Pisa: Edizioni ETS.

Allen, Prudence. 2002. The Concept of Woman, vol. II: The Early Humanist Reformation, 1250-1500. Cambridge: Wm. B. Eerdmans Publishing Co.

Alvar, Carlos. 2001. "Boccaccio en Castilla: entre recepción y traducción». Cuadernos de Filología Italiana no extraordinario 3: 330-350.

Andrés, Ramón. 2015. Semper dolens. Historia del suicidio en Occidente. Barcelona: Acantilado.

Archer, Robert. 2001. Misoginia y defensa de las mujeres. Antología de textos medievales. Madrid: Cátedra.

Beceiro Pita, Isabel y Ricardo Córdoba de la Llave. 1990. Parentesco, poder y mentalidad. La nobleza castellana (siglos XII-XV). Madrid: CSIC.

Bianchini, Janna. 2012. The Queen's Hands. Power and Authority in the Reign of Berenguela of Castile. Filadelfia: University of Pennsylvania Press.

Burke, Peter. 2016. «El sentido del anacronismo, de Petrarca a Poussin». En apéndice de El sentido del pasado en el Renacimiento, 177-197. Madrid: Akal.

Cardelle de Hartmann, Carmen. 2007. Lateinische Dialoge, 1200-1400. Literaturhistorische Studie und Repertorium. Leiden-Boston: Brill.

Cátedra, Pedro Manuel. 1989. Amor y pedagogía en la Edad Media. Salamanca: Universidad de Salamanca.

Cossutta, Fabio. 1984. Gli umanisti e la retorica. Roma: Edizioni dell'Ateneo.

Curtius, Ernst Robert. 1960. "Nomina Christi». En Gesammelte Aufsätze zur romanischen Philologie, 373-375. Berna-Múnich: Francke Verlag.

Duby, George. 1990. "À propos de l'amour que l'on dit courtois». En Mâle Moyen Âge. De l'Amour et autres essais, 74-82. París: Flammarion.

Duby, George. 1995. Dames du XIIe siècle. 1. Héloïse, Aliénor, Iseut et quelques autres. París: Gallimard.

Du Cange, Charles. 1883-1887. Glossarium mediae et infimae latinitatis. 10 vols. Niort: L. Favre.

Fernández Gallardo, Luis. 1996. «Traducciones castellanas del siglo XV. Ecos ciceronianos y aristotélicos en las Coplas de Jorge Manrique». Livius 8: 65-72.

Fernández Gallardo, Luis. 2000. El humanismo renacentista. De Petrarca a Erasmo. Madrid: Arco/Libros.

Fernández Gallardo, Luis. 2002. "Disidencia política y nuevos valores nobiliarios en Generaciones y semblanzas». En la España Medieval 25: 267-297.

Fernández Gallardo, Luis. 2007. «Alonso de Cartagena y la literatura humanística. Epístola y diálogo». Revista de poética medieval 19: 49-92.

Fernández Gallardo, Luis. 2012a. «Lengua e identidad nacional en el pensamiento político de Alonso de Cartagena». e-Spania, 13. https://doi.org/10.4000/e-spania.21012

Fernández Gallardo, Luis. 2012b. La obra literaria de Alonso de Cartagena (1385-1456). Ensayo de historia cultural. Saarbrücken: EAE.

Fernández Gallardo, Luis y Teresa Jiménez Calvente. 2015. El Duodenarium (ca. 1442) de Alfonso de Cartagena. Cultura casteIlana y letras latinas en un proyecto inconcluso. Córdoba: Almuzara.

Gómez, Jesús. 1988. El diálogo en el Renacimiento español. Madrid: Cátedra. 
Gómez, Jesús. 2000. El diálogo renacentista. Madrid: Ediciones de Laberinto.

Gómez Redondo, Fernando. 2002. Historia de la prosa medieval castellana. T. III Los orígenes del humanismo. El marco cultural de Enrique III y Juan II. Madrid: Cátedra.

González Rolán, Tomás, Antonio Moreno Hernández y Pilar Saquero Suárez-Somonte. 2000. Humanismo y teoría de la traducción en España e Italia en la primera mitad del siglo XV. Madrid: Ediciones Clásicas.

González Rolán, Tomás y Pilar Saquero Suárez-Somonte. 2014. «Textos castellanos cuatrocentistas sobre dos mujeres de la Antigüedad romana abocadas al suicidio: Lucrecia y Sofonisba». Cuadernos de Filología Clásica. Serie Latina 34: 74-100

Goody, Jacques. 2009. La evolución de la familia y el matrimonio. Valencia: Universitat de València.

Harth, Helene. 1983. «Poggio Bracciolini und die Brieftheorie des 15. Jahrhunderts. Zur Gattungsform der humanistischen Briefs». En Der Brief im Zeitalter der Renaissance, ed. Franz Josef Worstbrock, 81-99. Weinheim: Acta humaniora.

Jiménez Calvente, Teresa. 2015. "Alonso de Cartagena y la cuarta cuestión del Duodenarium: hacia un ensayo del género dialógico». eHumanista 29: 133-151.

Kristeller, Paul Oskar. 1974. "The Scholar and his Public in the Late Middle Ages and the Renaissance». En Medieval Aspects of Renaissance Learning. Three Essays by Paul Oskar Kristeller, ed. Edward P. Mahoney, 3-25. Durham: Duke University Press.

Lawrance, Jeremy, ed. 1979. Un tratado de Alonso de Cartagena sobre la educación y los estudios literarios. Bellaterra: Universidad Autónoma de Barcelona.

Lawrance, Jeremy. 1986. "On Fifteenth-Century Spanish Vernacular Humanism». En Medieval and Renaissance Studies in Honour of Robert Brian Tate, ed. Ian Michael y Richard Andrew Cadwell, 63-79. Oxford: Oxford University Press.

Lawrance, Jeremy. 1988. «Nuevos lectores y nuevos géneros: apuntes y observaciones sobre la epistolografía en el primer Renacimiento español». En Literatura en la época del Emperador, ed. Víctor García de la Concha, 81-99. Salamanca: Universidad de Salamanca.

Le Bras, Gabriel. 1968. "Le mariage dans la theólogie et le droit de l'Église du XI ${ }^{\mathrm{e}}$ au XIII ${ }^{\mathrm{e}}$ siècle». Cahiers de civilisation médiévale 42: 191-202.

Lehmann, Paul. 1941. «Konstanz und Basel als Büchermärkte während der grossen Kirchenversammlungen». En Erforschung des Mittelalters, t. I, 253-280. Stuttgart: Anton Hiersemann.

Lida de Malkiel, María Rosa. 1962. La originalidad artística de La Celestina. Buenos Aires: EUDEBA.

Marsh, David. 1980. The Quattrocento Dialogue. Classical Tradition and Humanist Innovation. Cambridge, Massachusetts - Londres: Harvard University Press.

Menéndez Pidal, Ramón. 1973. "Notas al libro del Arcipreste de Hita» (1898). En Poesía árabe y poesía europea, 145-150. Madrid: Espasa-Calpe.

Morrás, María. 1991. «Repertorio de obras, manuscritos y documentos de Alfonso de Cartagena». Boletín Bibliográfico de la Asociación Hispánica de Literatura Medieval 5: 213-248.

Morrás, María. 2003. "Alfonso de Cartagena». En Filológico de Literatura Medieval Española. Textos y documentos, Carlos Alvar y José Manuel Lucía Megías, 93-127. Madrid: Castalia.

Otis-Cour, Lewis. 2000. Historia de la pareja en la Edad Media. Placer y amor. Madrid: Siglo XXI.
Reynolds, Philip Lyndon. 1994. Marriage in the Western Church. The Cristianization of Marriage during the Patristic and Early Medieval Periods. Londres - Nueva York: E. J. Brill.

Ríos de la Llave, Rita. 2018. "No hay que tolerar a aquellos que con boca de perro intentan hablar mal de las mujeres": Alonso de Cartagena, la cuarta cuestión del Duodenarium y la Querella de las mujeres». Medievalismo 28: 203-233. https://doi. org/10.6018/345091

Ruiz Arzálluz, Íñigo. 2009. "Petrarca y los De viris illustribus». En Las biografías griega y latina como género literario, de la Antigüedad al Renacimiento: algunas calas, ed. Vitalino Valcárcel, 155-158. Vitoria: Universidad del País Vasco.

Salvador Martínez, Heraclio. 2012. Berenguela la Grande y su época (1180-1246). Madrid: Ediciones Polifemo.

Sánchez-Albornoz, Claudio. 2001. España, un enigma histórico. 2 vols. Barcelona: Edhasa.

Schiff, Mario. 1905. La bibliothèque du Marquis de Santillane. París: Librairie Émile Bouillon.

Schmitt, Jean-Claude. 1976. "Le suicide au Moyen Âge». Annales ESC 31 (1): 3-28.

Schoh, R. 1986. "A Century of Nuremberg Printmaking», en Gothic and Renaissance Art in Nuremberg, 1300-1550, 93-100. Múnich: Prestel Verlag.

Suárez Fernández, Luis. 1975. Nobleza y monarquía. Puntos de vista sobre la historia política castellana del siglo XV. Madrid: Universidad de Valladolid.

Tate, Robert Brian, ed. 1965. Fernán Pérez de Guzmán, Generaciones y semblanzas. Londres: Tamesis.

Unamuno, Miguel. 2009. El espejo de la muerte y otros relatos. Madrid: Alianza Editorial.

Valero Moreno, Juan Miguel. 2015a. «Guía para el estudio de Petrarca en la península ibérica». Quaderns d'Italia 20: 191-213.

Valero Moreno, Juan Miguel. 2015b. «Antecedentes y encrucijadas de la vida activa y contemplativa en la Castilla del Cuatrocientos». eHumanista 29: 32-71.

Vaquero, Mercedes. 2003. Cultura nobiliaria y biblioteca de Fernán Pérez de Guzmán. Ciudad Real: Ediciones Oretania.

Vélez-Sainz, Julio. 2015. La defensa de la mujer en la literatura hispánica. Siglos XV-XVII. Madrid: Cátedra.

Vian, Ana. 1988. «La ficción conversacional en el diálogo renacentista». Edad de Oro 7: 173-188

Vian, Ana. 2001. «Interlocución y estructura de la argumentación en el diálogo: algunos caminos para una poética del género». Criticón 81-82: 157-190.

Walsh, John K, ed. 1975. Libro de los doze sabios o Tractado de la nobleza y lealtad. Madrid: Real Academia Española.

Weiss, Julian. 1991a. "Fernán Pérez de Guzmán: Poet in Exile». Speculum 66: 96-108.

Weiss, Julian. 1991b. «Álvaro de Luna, Juan de Mena and the Power of Courtly Love». Modern Language Notes 106: 241-256.

Weiss, Julian. 2002. “¿Qué demandamos de las mujeres?” Forming the Debate about Women in Late Medieval Spain». En Gender in debate. From the Early Middle Ages to the Renaissance, ed. Thelma S. Fenster y Clare A Lees, 237-281. Nueva York: Palgrave.

Zappala, Michael. 1989. «'Fablemos latino': diálogo, Latin Roots and Vernacular Landscape in fifteenth and sixteenth century Castile». Ibero-romania 29: 43-64. 